\title{
La «calidad social»: un nuevo paradigma en las políticas europeas
}

\section{Vicente Pérez Menayo *}

\section{La calidad como parte de la retórica contemporánea}

Aunque el término calidad se encuentra cada vez más en boga entre gestores y políticos, también constituye una importante fuente de confusión conceptual y cultural. Como señala un experto en calidad: «la calidad es muy simple, tan simple que es difícil que la gente la entienda» (Roger HaLE).

Según la Real Academia Española de la Lengua, calidad es la propiedad o propiedades inherentes a una cosa que permiten apreciarla como igual, mejor o peor que las restantes de su especie. Si atendemos a las definiciones dadas por los más importantes especialistas:

- calidad es el grado de satisfacción del consumidor por el producto o servicio adquirido (FeIGenbaun, 1961);

- calidad es desarrollar, diseñar, producir y servir un producto o servicio lo más económico, útil y siempre satisfactorio para el cliente (ISHIKAWA, 1985);

- calidad es el ajuste de un producto o un servicio a los requerimientos del cliente (CROSBY, 1987);

- calidad es la satisfacción plena de la sociedad (DEMING, 1989);

- calidad es el conjunto completo de actividades de las cuales alcanzamos la aptitud para el uso (JURAN, 1990).

Entre las diversas definiciones expresadas, retenemos, para el objetivo de este trabajo, la ofrecida por Deming: calidad es la satisfacción plena de la sociedad, ya que su estrategia de calidad, desde una perspectiva totalizadora de satisfacción social, aunque no es la única, es con mucho la más influyente y extendida.

Existen diferentes razones que explican el creciente aumento de la importancia que se atribuye a la calidad: 1) el incremento global de la competencia, que obliga a las organizaciones a plantearse continuamente la forma de producir y ofrecer mejores servicios y más adaptados a las nuevas demandas; 2) la internacionalización de los mercados, que hace necesario implantar mecanismos de calidad que permitan a los clientes orientarse en ámbitos cada vez menos conocidos; los sistemas de calidad constituyen señales de identificación, que ayudan a situarse en contextos cada vez más globalizados; 3) el aumento de las exigencias de los consumidores, cada vez más conscientes de sus derechos sobre los productos que compran o los servicios que reciben y dispuestos a reclamar, en caso de no conseguir la calidad esperada (OsCa Segovia, 2000).

Por su parte, las organizaciones públicas de los países europeos más desarrollados han experimentado también, desde la mitad de la década de los ochenta, un fuerte movimiento de transición hacia modelos de comportamiento que buscaban un mayor equilibrio en las relaciones de intercambio entre las instituciones públicas proveedoras y los consumidores de servicios públicos. Este movimiento fuerza a las organizaciones públicas a renovar sus códigos de conducta y adopta el lenguaje de moda en el mundo empresarial (Pérez Menayo, 1996, 1998).

Así, la calidad se ha convertido en un término fundamental de nuestra retórica contemporánea, que también se ha introducido en los procesos de modemización del modelo social europeo preconizados por la Agenda Social Europea, aprobada por 
el Consejo Europeo de Niza a finales del año 2000. Lo cierto es que resulta difícilmente imaginable que alguien pueda desear oponerse a la calidad, al igual que no parece posible oponerse a la virtud (PoLLTT, 1995).

La satisfacción con calidad de las nuevas necesidades sociales abre una vía innovadora para la aplicación de nuevos conceptos: surge la calidad social. A lo largo de las páginas que siguen se va a profundizar en este concepto recogiendo el testigo planteado por los profesores BECK, MAESEN y WALKER (1997), editores de la obra colectiva The Social Quality of Europe. Estos autores señalaban la necesidad de progresar en la conceptualización de la calidad social, necesitada de ajustes tanto teóricos como prácticos.

En este sentido, el autor de este trabajo se inclina por un enfoque «managerial». Para ello, se aborda la identificación de aquellos criterios que configuran el Modelo Europeo de Excelencia de la European Foundation for Quality Management (EFQM), y su relación con los conceptos de calidad del trabajo, de las relaciones laborales y de la política social, que se contemplan en la Agenda Social Europea (ver apartado 3). Se trata de un ejercicio arriesgado, no exento de ciertas licencias que se permite el autor de este trabajo, si tenemos en cuenta que el Modelo Europeo de Calidad se aplica a los productos y a los servicios. Sin embargo, nuestro objetivo no es otro que intentar una sistematización que pueda permitir, en su día, la evaluación de la calidad social, huir de elementos intangibles, e intentar visualizar los atributos y criterios que configuran dicha calidad social.

Sin perjuicio de las definiciones sobre la calidad social que se contemplan más adelante, elaboradas por cualificados expertos, el autor de estas páginas adelanta la siguiente:

«Calidad social significa contar con mejores puestos de trabajo y medios que permitan conciliar la vida profesional y la vida privada de los hombres y de las mujeres; lograr entornos de trabajo saludables que aseguren la motivación, la satisfacción y la participación de las personas, y estimulen la prolongación de la vida laboral por un tiempo más amplio que en la actualidad; asumir que el concepto de "empleabilidad de por vida" está dando paso al de "mantenerse en condiciones de ser empleado a lo largo de toda la vida", ya que se cuenta con las habilidades, las destrezas y las capacidades requeridas; finalmente, procurar, a las personas que lo deseen, un "envejecimiento activo", remunerado y contributivo, que ayude a disminuir las tensiones financieras futuras de los sistemas de protección social y asegure la solidaridad entre las generaciones.»

\section{Hacia la «calidad social»}

A continuación se va a abordar el concepto de calidad social desde tres aspectos: ético, jurídico y organizativo -ver Gráfico 1.

Gráfico 1

\section{DEFINICIÓN DE LA CALIDAD SOCIAL}

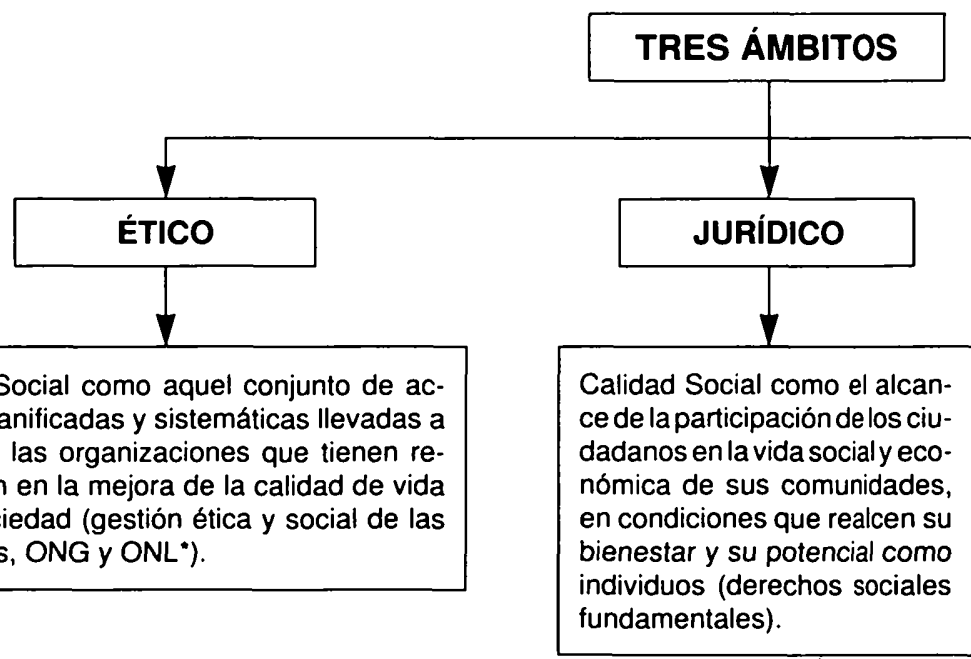

- ONL: Organizaciones no lucrativas. 


\subsection{Un nuevo escenario: el enfoque ético}

En los últimos años se vislumbran nuevas perspectivas que vienen a complementar y enriquecer los conceptos que rigen la gestión integral de las organizaciones: se comienza a hablar de la calidad social. La calidad social se sitúa actualmente entre los factores que favorecen la fidelidad de los clientes mediante el aumento de las exigencias de éstos hacia una cierta corresponsabilización de las empresas respecto a la adquisición de productos con problemáticas sociales, ecológicas u otras por las cuales el cliente se siente sensibilizado (consumidor vigilante).

Para ilustrar mejor el escenario que se va configurando como consecuencia del aumento de una nueva sensibilidad social, repasaremos a continuación, siguiendo a MIRMI CLUA (2000), algunos de los últimos acontecimientos que se han producido:

- La importancia económica de la sociedad civil y su contribución al crecimiento económico y la cohesión social. Con otras palabras, el incremento considerable de la actividad de lo que se ha venido denominando sector no lucrativo (non profit organizations). Definir este sector puede resultar una trampa. $\mathrm{Ni}$ las actividades de voluntariado, ni la designación sin fines de lucro ofrecen una descripción precisa. Como clarifican OSBORNE y GAEBLER (1994), este sector está formado por organizaciones de propiedad y control privados, pero cuya existencia tiene por finalidad la satisfacción de necesidades públicas o sociales y no la acumulación de riqueza privada. Tampoco es exacto que no tengan fines de lucro y que se nutran fundamentalmente de voluntarios, ya que muchas de estas organizaciones obtienen «ganancias» y emplean a profesionales a sueldo. A falta de formular mejor este concepto, llamamos tercer sector a este grupo de instituciones.

Los últimos datos comparados conocidos (Jobns Hopkins University, Baltimore, USA, 1998), relativos a 22 países (de los cuales 9 son Estados miembros de la UE) son elocuentes:

- el sector asociativo en los 22 países examinados representaba una «industria» equivalente de media al $4,7 \%$ del PIB (5,7\% si se incluye el voluntariado);

- emplea a unos 19 millones de trabajadores a tiempo completo (es decir el $4,9 \%$ del empleo total y un $9,4 \%$ del empleo en el sector servicios);

- en cuanto a España, el estudio citado indicaba que en nuestro país había, a mediados de los noventa, 253.309 organizaciones privadas sin ánimo de lucro, que empleaban a un millón de voluntarios que dedicaban más de 4 horas por semana a acciones sociales, y cerca de tres millones que colaboraban esporádicamente. España ocupa el décimo lugar en relación al número de trabajadores empleados en asociaciones no lucrativas con un $4,5 \%$ de la población activa, al mismo nivel que Alemania. Toda la actividad generada por este sector en España se cuantifica en un $4,04 \%$ del PIB.
Una encuesta, en la que participaron más de 20.000 personas de toda Europa, llegó a la conclusión de que uno de cada cuatro europeos realiza alguna actividad no remunerada para una variedad de causas caritativas y de grupos de voluntarios (Comisión Europea, 2000).

- Otro fenómeno que podemos encontrar en el mismo contexto es la aparición de fondos éticos o bonos de solidaridad que pretenden captar a inversores sensibles a las problemáticas sociales. La gestora norteamericana Domini, pionera en este campo, creó el primer índice, que recibe el nombre de Domini 400 Social Index, formado por 400 empresas comprometidas explícitamente con la comunidad y el medio ambiente y que, además, alcanzan una alta rentabilidad. El Dow Jones Sustainability también agrupa a las empresas que cumplen códigos éticos y que son las depositarias de las inversiones de los fondos éticos que, por definición, sólo pueden invertir en ellas (TEJERA Oliver, 2001).

- Desde una perspectiva más cercana a la realidad cotidiana de las empresas, esta sensibilidad ya ha intentado materializarse en algunos referentes y modelos de gestión. A las incipientes consideraciones sobre el tema de la nueva ISO 9000: 2000, y a los de más alcance del Modelo Europeo de Excelencia de la EFQM (por ejemplo, el criterio sobre el impacto de la organización en la sociedad), a los que se hace referencia en el apartado 3, hay que añadir la norma SA8000 (Social Accountability) promovida por el Council on Economic Priorities Acreditation Agency (CEPAA), que tiene como objetivo acreditar -y también certificar- que los productos de una empresa ban sido producidos en condiciones laborales equivalentes a las de los paises en los que serán consumidos (esta norma está basada en los Convenios de la OIT, la Declaración Universal de Derechos Humanos y la Declaración de Derechos del Niño de la ONU). Asimismo, el Documento AA 1000 del Institute of Social and Etbical Accountability fue elaborado en 1999 para mejorar el comportamiento de las empresas y organizaciones, aumentando la calidad de sus actuaciones éticas y sociales. Finalmente, las memorias de sostenibilidad basadas en las guías del Global Reporting Iniciative (GRI) están destinadas a informar a la sociedad sobre los aspectos económicos, medioambientales y sociales de las actividades, procesos, productos y servicios de una empresa (Tejera Oliver, 2001).

Sin la intención de construir un término definitivo, MRRI CluA adelanta una definición de la calidad social, como aquel conjunto de acciones planificadas y sistemáticas llevadas a cabo por las organizaciones que tienen repercusión en la mejora de la calidad de vida del conjunto de la sociedad. Considerar el alcance de esta definición circunscrita exclusivamente al mundo empresarial sería un importante error de concepto: no sólo las empresas tienen un impacto y una responsabilidad social, sino también las acciones realizadas por todas las demás organizaciones (lucrativas, no lucrativas - ONL-; públicas o privadas...). 
Si bien la gestión y el aseguramiento de la calidad ha dado a las organizaciones que los han implantado un referente para las mismas y una coherencia de sus sistemas internos, es posible que las guías de actuación de las estrategias de calidad de cara al exterior de la organización vengan marcadas por criterios de calidad social.

Estamos en presencia de un nuevo escenario que considera especialmente las repercusiones sociales de la actividad empresarial, y muy particularmente en el ámbito del Derecho del trabajo, remarcando el concepto de responsabilidad social como un nuevo valor a ser considerado dentro de los mecanismos habituales de gestión. La legitimación de la empresa ante la sociedad requiere el desarrollo de un nuevo discurso sobre calidad social que incorpore decididamente los valores éticos que proporcionarán a las organizaciones unos elementos de identidad, legitimación y diferenciación, indispensables también para alcanzar el éxito empresarial (Mirmi ClUA, 2000). Las Conclusiones del Consejo Europeo de Lisboa lanzan un proceso de creación de una red para un diálogo europeo que favorezca la responsabilidad social de las empresas. En este sentido, el Consejo Europeo llama especialmente la atención, en cuanto a la responsabilidad social de las empresas, respecto a las mejores políticas en materia de educación y formación a lo largo de la vida, la organización del trabajo, la igualdad de oportunidades, la integración social y el desarrollo sostenible. Por su parte, la Agenda de Política Social de la Comisión (junio de 2000 ) ha dado prioridad a la responsabilidad social de las empresas señalando su importancia para hacer frente a las consecuencias del empleo, y de la adaptación de las condiciones de trabajo y de las relaciones contractuales de la nueva economía.

En este sentido, entre las iniciativas suscitadas a nivel comunitario, hay que señalar la elaboración de un Libro Verde sobre la Responsabilidad Social de las Empresas (RSE), para junio de 2001 (Consejo Europeo de Estocolmo, marzo de 2001). Los debates sobre el label social (etiqueta social, cuyo objetivo es garantizar un comercio equitativo o «leal»), así como el label ecológico (etiqueta ecológica: promover productos o servicios que pueden reducir sus efectos ambientales adversos, contribuyendo a un uso eficaz de los recursos y a un elevado nivel de protección del medio ambiente), constituyen conceptos que tienen impacto en la sociedad.

Los responsables del Congreso de Empresas de Calidad, que se celebra anualmente en Barcelona, han estimulado el debate en torno a lo que se ha dado en denominar la gestión ética. El objetivo consiste en proyectar los valores éticos de las personas en la gestión de las organizaciones (URTLAGA, 2000). El Foro para la Evaluación de la Gestión Ética creado recientemente en España (Forética, 2000) ha comenzado a desarrollar sus actividades en dos vertientes:

- la evaluación de los programas de actuación en cuanto a fines y objetivos (para las organizaciones, en general), y
- la evaluación de la adecuada aplicación de fondos (para las ONGs, en particular).

Con esta iniciativa se trataría de evaluar, e incluso certificar, la calidad ética en las organizaciones lucrativas y no lucrativas. Tanto las normas ISO 9000 como el Modelo Europeo de Excelencia proporcionan experiencias que pueden permitir objetivar la gestión ética (URTIAGA, 2000). En el ámbito de actuación de AENOR (Asociación Española de Normalización y Certificación) se ha creado un Comité técnico de normalización que trata de los aspectos éticos en la gestión de las empresas, ONGs y actividades profesionales, incluyendo:

- instrumentos financieros éticos;

- gestión ética y social de las empresas;

- códigos éticos profesionales;

- sistema de gestión para ONGs, ONLs (organizaciones no lucrativas) y organizaciones de inserción social.

En definitiva, se trata de influir en el comportamiento de las empresas asegurando su reputación corporativa siendo económicamente viables, socialmente beneficiosas y ambientalmente responsables (HuRTADo, 2001). Todo ello, con el objetivo de conseguir una sociedad más justa y un desarrollo sostenible. Así, la Comisión Europea ha presentado un informe (marzo de 2001) en el que identifica seis aspectos para lograr un desarrollo sostenible dentro de la Unión Europea:

- cambio climático y efectos directos;

- amenazas para la salud pública;

- presión sobre algunos recursos naturales;

- pobreza y exclusión social;

- implicaciones del envejecimiento de la población;

- movilidad de la contaminación.

Este primer paso ha continuado con una proposición para la creación de una Estrategia de Desarrollo Sostenible, que la Comisión presentó a la Cumbre de Goteburgo (Suecia, junio de 2001).

\subsection{Un concepto integrado de la calidad social: el enfoque jurídico}

Siguiendo al profesor OjEDA AvLÉs (1998) en la búsqueda de un concepto «integrativo» de la calidad social, la perspectiva jurídica debe partir de los instrumentos legales existentes en la UE, y en especial del Tratado de la Comunidad Europea, con las trascendentales reformas a que ha sido sometido en sus cuarenta y cuatro años de vigencia.

Los profesores BECK, MAESEN y WALKER (1997) proponen un nuevo modelo mediante el cual se puedan calibrar las politicas económicas y sociales; un modelo que podría usarse a todos los niveles en la UE para evaluar en qué medida la vida 
cotidiana de los ciudadanos más vulnerables ha alcanzado un nivel inaceptable, así como la dirección que parecen indicar los posibles cambios. Este modelo se denomina calidad social. Inicialmente, se podría definir como el alcance de la participación de los ciudadanos en la vida social y económica de sus comunidades, en condiciones que realcen su bienestar y su potencial como individuos. Por lo tanto, el nivel de calidad social experimentado por los ciudadanos radica en:

- el grado de seguridad económica;

- el nivel de integración social;

- la amplitud de la cohesión social y la solidaridad, y

- el nivel de autonomía o poder de decisión.

Está claro que estos conceptos son mucho más amplios que los modelos sociales existentes. Son, además, tentativos y no han sido demostrados empíricamente. Dichos autores consideran está definición del concepto de calidad social solamente como un primer paso, y reconocen que requiere mayores ajustes. Llegan a afirmar que vamos camino de establecer una Fundación Europea sobre la Calidad Social, que esperan llegue a ser un punto central para continuar los estudios sobre la teoría y la práctica de la calidad social y se convierta en el eje de una red de investigación destinada a la evaluación de los cuatro conceptos citados, en cada uno de los Estados miembros de la UE.

Por lo tanto, la calidad social, desean BECK, MAESEN y WALKER que sea tanto un patrón con el que los ciudadanos europeos puedan medir la eficacia de las políticas nacionales y europeas, como un criterio en el que fundarse a la hora de establecer políticas. Además, podría suponer la base para una reordenación entre la política económica y la política social, siendo la calidad social el objetivo de ambas políticas. Como señala BRUTO DA CosTa (1997), el crecimiento económico no es un fin en sí mismo, mientras que la calidad social debería ser el objetivo final del crecimiento. Los investigadores sociales tienen que demostrar, enfatizan los autores citados, que la calidad social de la vida europea no es un concepto orientado hacia el pasado, para defender un alto nivel de protección social y de gasto social, sino que constituye el futuro objetivo general de la unificación europea, que le confiere un alto valor y un sentido humano.

Comentando las limitaciones del acervo comunitario en materia social, los profesores SCHULTE (1997) y PIETERS (1997) llegan a una serie de importantes coincidencias, dentro de las cuales mantienen algunas matizaciones:

- Insuficiencia de los medios legales comunitarios. Las reformas del Tratado han ampliado moderadamente las habilitaciones legislativas, pero como contrapartida han introducido también el principio de subsidiariedad que en opinión de los dos autores citados puede imponer fuertes limitaciones a la intervención comunitaria en problemas sociales; opinión que cree el profesor OJEDA AvLÉs (1998) dominante entre los expertos, quienes se esfuerzan actualmente en superar ese impedimento potencial mediante combinaciones entre subsidiariedad y solidaridad.

- Anquilosamiento del modelo europeo de protección social. Especialmente el sistema europeo de libre circulación y de coordinación de la seguridad social gira en torno al trabajador, cuan. do la sociedad ha evolucionado hacia una pérdida de importancia de esta figura y una ampliación de las personas sin empleo y del sector voluntario. Los autores citados (SCHUlte y PIETERS), añade el profesor OJEDA AvLÉs, se muestran de acuerdo en la necesidad de actualizar el modelo. No obstante, conviene señalar que la simplificación emprendida del Reglamento 1408/71 y los trabajos iniciados en el Consejo, por el Comité de Protección Social, respecto a la fijación de los objetivos de lucha contra la pobreza y la exclusión social, y a la viabilidad y sostenibilidad de los sistemas de pensiones, constituyen la manifestación de la voluntad política de abordar la modernización de los sistemas de protección social europeos en el ámbito comunitario.

- Insuficiencia de los contenidos legales comunitarios. Los citados autores señalan como el principal vacío la ausencia de un capítulo social con un listado de derechos fundamentales dentro del Tratado CE. Más allá de las leyes existe, como señala SCHULTE, una living constitution europea, lo que otros autores denominan el modelo social europeo. Esa «constitución viviente» es la que habría que incorporar al Tratado, pero como hay diferencias entre unos Estados miembros y otros, el problema que puede plantearse consiste en fijar qué mínimo de armonización social requiere la culminación de la Unión Europea.

- No inclusión, de momento, en el Tratado de los derechos sociales contenidos en la Carta de Derechos Fundamentales de la Unión Europea. Como mínimo hubiera sido deseable una referencia a la Carta en el artículo 6 del Tratado de la UE, revisado en Niza (Conferencia Intergubernamental, 2000), pero las dificultades de una minoría de Estados miembros no lo hizo factible. No obstante, cabe esperar que el proceso surgido de la declaración sobre el futuro de la Unión, del Tratado de Niza, permita avanzar en el sentido señalado ya que, entre los asuntos a abordar en un futuro inmediato está qué estatuto conceder a la Carta de Derechos Fundamentales de la Unión Europea (ver Gráfico 2). En la línea manifestada por PIETERS, así la Unión no se limitaría únicamente a proclamar como derechos europeos lo que ya está reconocido por los Estados miembros. En cuanto a la identificación de los derechos sociales y a su inclusión en el Tratado, el profesor OJEDA AvLÉs avanza una línea de investigación útil para interpretar los avances integradores del nuevo concepto de calidad social desde una perspectiva jurídica. Se trata de que, a pesar de la aparente heterogeneidad de los derechos sociales que se han ido reconociendo por el Tratado, los reglamentos y las directivas en materia social, existe un hilo conductor que ha orientado el conjunto 


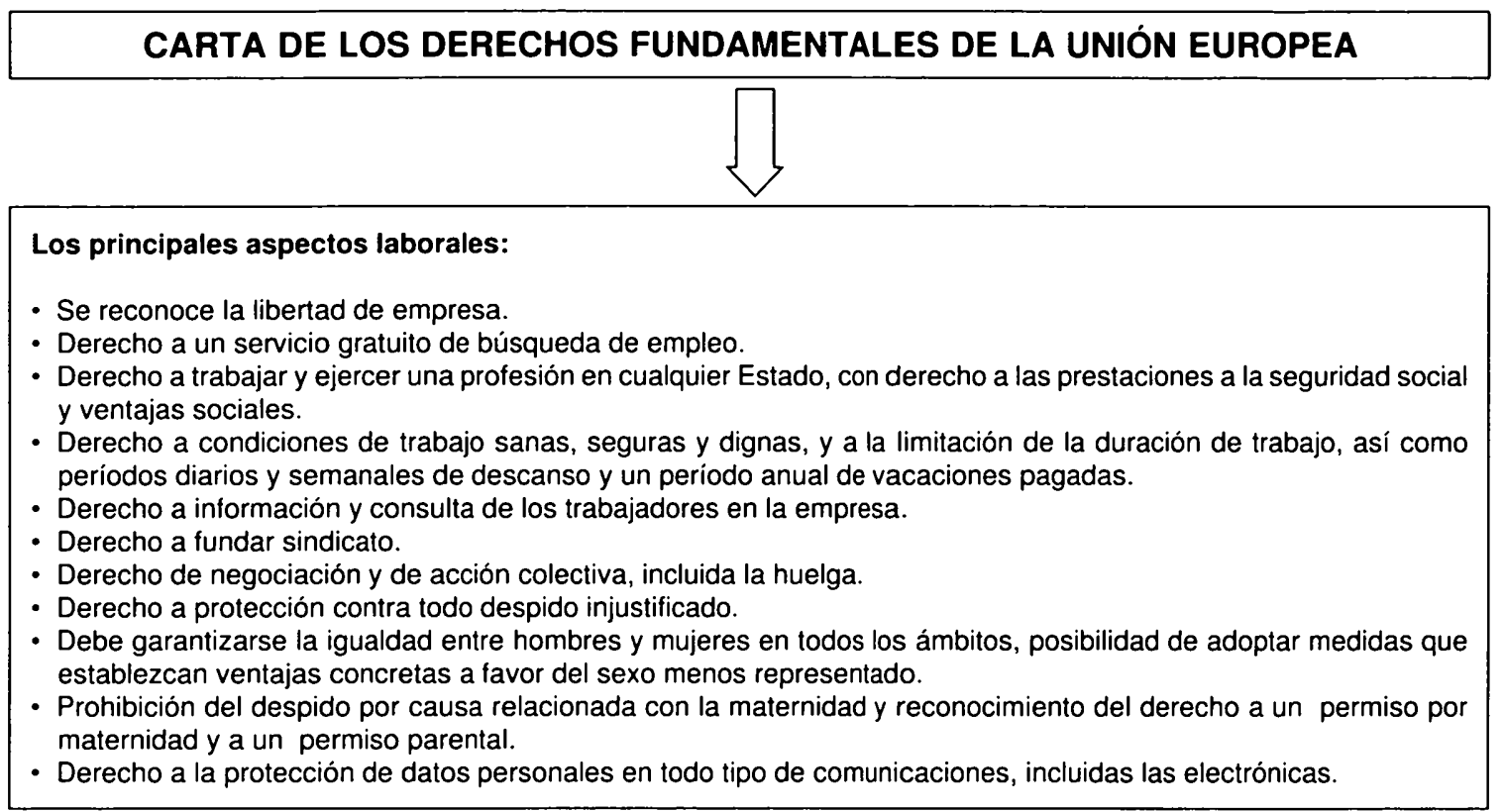

Fuentc: Noticiario Juridico Aranzadi (octubre 2000) y Cara de Derechos Fundamentales de la UE (diciembre 2000).

del avance y que puede servirnos para determinar el alcance de los retos futuros.

\subsection{El trabajo en mutación: el enfoque organizativo}

En el contexto económico actual, marcado por el paso de un universo cerrado y dirigista a un universo abierto y competidor, se está produciendo, además, la mutación del entorno de trabajo (nuevas profesiones, necesidad de nuevas habilidades, destrezas y capacidades, nuevas organizaciones emergentes...). La globalización de los intercambios sitúa a la UE y a sus Estados miembros en un momento crucial para competir a escala de los grandes bloques económicos. El $42 .^{\circ}$ Congreso Europeo de Calidad, celebrado en París en octubre de 1998, realizó una encuesta entre más de dos millares de expertos sobre qué actuaciones tendrían más impacto en el incremento de la competitividad en Europa. La mayoría (54\%) se decantó por el Knowlege Management (capacidad de la organización para gestionar el conocimiento) y el Learning Organization (capacidad de aprendizaje colectivo de una organización). Ambos conceptos agregados conformarían lo que, desde hace más de una década, se viene denominando Gestión del Conocimiento (Udaondo, 1999) —ver Gráfico 3.

Aunque el concepto de Learning Organization no es nuevo (CROZIER, 1970; ARGYrIS, 1977), la última etapa de la evolución del término se produce en los años noventa. Entre las múltiples definiciones del concepto, seleccionamos dos que nos parecen significativas:

- la organización que aprende es aquella que facilita el aprendizaje a todos sus miembros y que se transforma continuamente (GARRAT, 1990);

- una organización que aprende es experta en crear y adquirir conocimientos y transmitirlos, así como modificar parcialmente su trayectoria a la luz de nuevos conocimientos y hallazgos (GARVIN, 1993).

Peter Drucker, uno de los pocos «gurus» de la ciencia de la gestión respetados, ya abogaba, a comienzos de la década de los ochenta, por una nueva clase de trabajadores del conocimiento (concepto ya acuñado por él en 1959). Asimismo, la principal finalidad de su obra The Concept of the Corporation (1983) era tratar las empresas como un sistema social, además de como una organización económica, es decir, la empresa como «esfuerzo humano», como «institución social»; otro de los temas de la obra de DRUCKER era que el antiguo proletariado iba a ser sustituido por trabajadores del conocimiento, apuntando que el mundo desarrollado estaba pasando de una «economía de bienes» a una «economía del conocimiento». Como resultado de todo ello, la gestión de las organizaciones se estaba transformando (MICKLETHWATT y WOOLDRIDGE, 1998).

Como señala la Agenda Social Europea, aprobada en la Cumbre de Niza en diciembre del 2000 (basada en la Comunicación de la Comisión «Agenda de Política Social», junio de 


\section{CONGRESO DE LA CALIDAD. PARÍS, 21 A 23 DE OCTUBRE DE 1998}

\section{¿Qué actuaciones tendrian un mayor impacto en el incremento de la competitividad en Europa?}

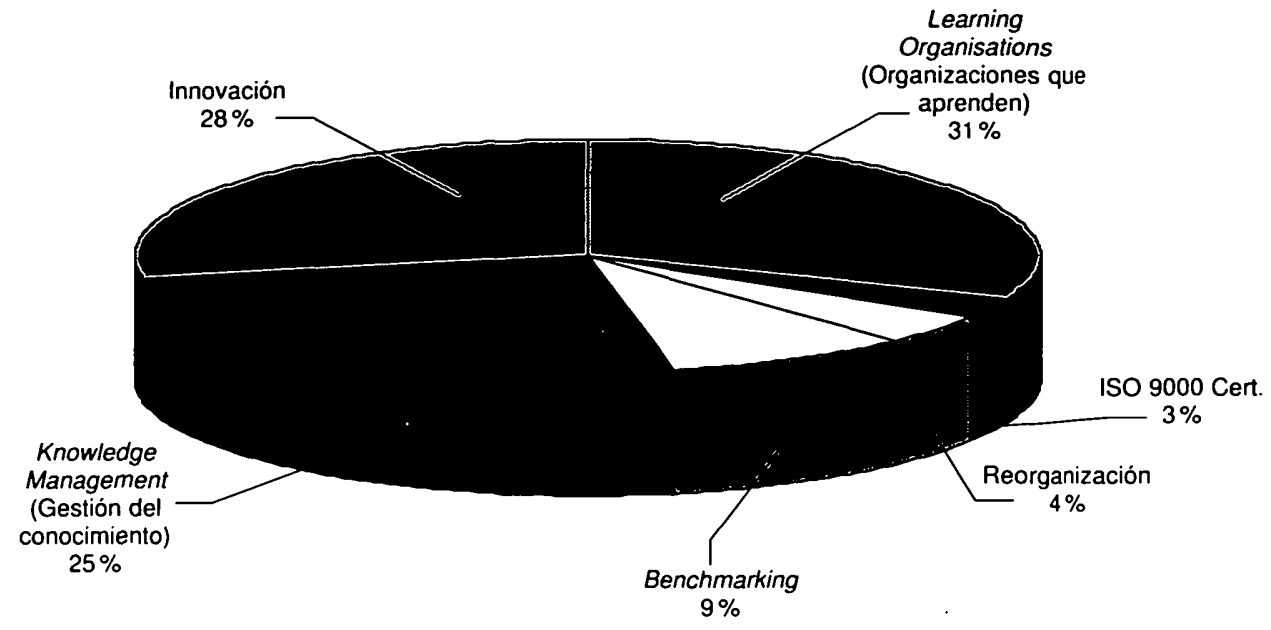

Fuente: Club Gestión de Calidad; M. Udłowdo Duris, Excelencie, núm. 22, enero 1999.

2000), la mundialización de los intercambios comerciales y financieros, al aumentar la competencia, agudiza la exigencia de competitividad, lo que tiene consecuencias sobre las políticas sociales (aquí cabe mencionar la repercusión de las cargas sociales en los costes salariales). Las negociaciones multilaterales de tipo predominantemente económico tienen cada vez más una dimensión social: téngase en cuenta, por ejemplo, los debates en torno a los derechos sociales fundamentales y los imperativos de la seguridad en materia de salud pública, a tenor de la crisis alimentaria actual que sacude a Europa (dioxinas, encefalopatía espongiforme bovina, fiebre aftosa; a menudo, estos acontecimientos tienen su origen en un comportamiento poco ético de las empresas y organizaciones relacionadas; a esto hay que añadir el debate sobre los productos transgénicos y las actividades de ingeniería genética que, también, siembran inquietud en la sociedad).

La propia Agenda de Política Social de la Comisión (junio de 2000) señala que el rendimiento de Europa en una economía internacionalizada se ve afectado por la calidad de los bienes y de los servicios que produce y comercializa, y por su valor añadido. Mejorar la calidad del trabajo significa aumentar la calidad de la producción con lo que se fortalece la posición competitiva de las empresas europeas. Pero, además, la UE tiene que continuar combinando las buenas condiciones sociales con la alta productividad de los bienes y servicios. Ésta es una de las características del modelo social europeo: más y mejor empleo en una economía dinámica y competitiva, que refuerce la cohesión social.
El tránsito de una Sociedad de la Información a una Sociedad del Conocimiento constituye uno de los retos fundamentales a los que se enfrenta la UE. En el marco de una sociedad basada en el conocimiento, está claro que los sistemas educativos y de aprendizaje continuo de la Unión deben ser capaces de satisfacer las necesidades de la sociedad en un entorno rápidamente cambiante, para asegurar que todos los grupos sociales tengan acceso a la formación. A pesar del considerable progreso realizado en cuanto a los niveles de educación durante las últimas décadas, algunos grupos de la sociedad siguen corriendo el riesgo de tener una formación deficiente (se estima que la penuria en competencias ligadas a las tecnologías de la información es en la UE de aproximadamente 1,4 millones de empleos en el 2001, y alcanzará los 1,7 millones en el 2003; Plan de Acción e-Learning, Comisión Europea, 2001). La Agenda Social Europea señala que la opción por una sociedad del conocimiento implica que se invierta en recursos humanos a fin de fomentar la cualificación y la movilidad de los trabajadores.

Anticiparse a los cambios del entorno de trabajo y sacar partido de los mismos, desarrollando un nuevo equilibrio entre la flexibilidad para las empresas y la seguridad para los trabajadores, es otra orientación relevante de la Agenda. Las profundas transformaciones de la economía y del trabajo se están acelerando en todos los Estados miembros, haciendo necesarias nuevas respuestas colectivas que tengan en cuenta las expectativas de los asalariados. El diálogo social y la concertación deben crear las condiciones necesarias para una participación de los asalariados en los cambios que se produzcan, mediante una anti- 


\section{Gráfico 4}

\section{MÉTODO ABIERTO DE COORDINACIÓN}

1. Establecer directrices para la Unión, combinadas con calendarios específicos para lograr los objetivos que establezcan a corto, medio y largo plazo.

3. Plasmar estas directrices europeas en medidas de política nacional y regional, estableciendo objetivos específicos y dando los pasos adecuados, sin perder de vista las diferencias nacionales y regionales.
2. Establecer, cuando proceda, indicadores y puntos de referencia cuantitativos y cualitativos cotejados con los mejores que existan y adpatados a las necesidades de los distintos Estados miembros y sectores, como método de comparación de las prácticas idóneas.

Fuente: Conclusiones Consejo Europeo de Lisboa, marzo 2000.

\section{Gráfico 5}

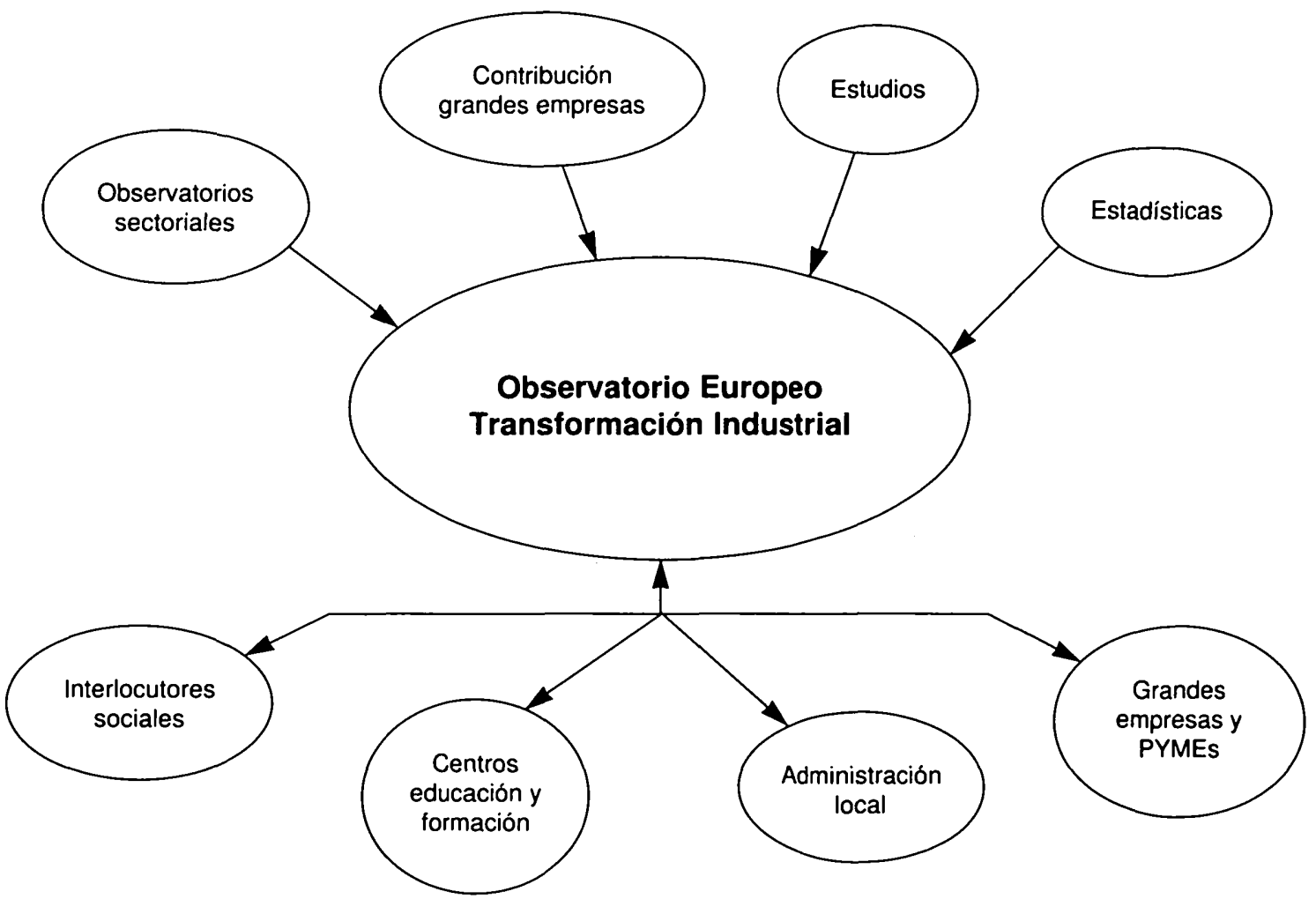

Fuente: Elaboración propia en base a: «Gestionar el Cambio», Comisión Europea, 1998; Conclusiones Consejo Europeo de Estocolmo, 2001. 
cipación de los cambios en las empresas, los sectores industriales y los territorios. La búsqueda de unos marcos colectivos innovadores y adaptados a las nuevas formas de empleo deberá permitir el fomento de la movilidad y de la inserción de las personas en unas situaciones profesionales cada vez más diversificadas, mediante la organización de transiciones entre situaciones o empleos sucesivos. Las medidas que se adopten para hacer frente a estas transformaciones deberán recurrir de manera equilibrada a los diferentes instrumentos comunitarios existentes, en particular el método abierto de coordinación (ver Gráfico 4) y dejar un margen de iniciativa a los interlocutores sociales (entre las medidas para desarrollar esta orientación cabe señalar la creación de un Observatorio Europeo de la Transformación Industrial, en el 2001 -ver Gráfico 5-).

El modelo social europeo se apoya hoy en día, por encima de la diversidad de los sistemas sociales de los Estados miembros, en una base común de valores. Para responder a estos nuevos desafíos, la Agenda Social Europea ha de garantizar la modernización y la profundización del modelo social europeo e insistir, en todos los ámbitos de la política social, en la pro- moción de la calidad. La calidad de la formación, la calidad del trabajo, la calidad de las relaciones laborales y la calidad de la política social son factores esenciales para que la Unión Europea cumpla los objetivos que se ha fijado en cuanto a competitividad y pleno empleo (Niza, 2000) —ver Gráfico 6.

La calidad del trabajo implica, para la Comisión, mejores puestos de trabajo y medios más equilibrados para conciliar la vida profesional con la vida privada. Esto aumentará el nivel de motivación y de satisfacción de los trabajadores lo cual beneficia a las personas, la economía y la sociedad en su conjunto. Para ello son necesarias mejores políticas de empleo, una remuneración equitativa y una organización del trabajo adaptada a las necesidades de las empresas y de las personas. Asimismo, la calidad se basa, según la Agenda, en altas cualificaciones, normas de trabajo equitativas y niveles correctos de salud y seguridad en el trabajo, y pasa, además, por facilitar la movilidad profesional y geográfica (ver Gráfico 7).

Por otra parte, la calidad de las relaciones laborales en un entorno de trabajo adecuado, que preconiza la Agenda de Polí-

\section{POLÍTICA SOCIAL}

\section{CALIDAD SOCIAL / COHESIÓN SOCIAL}

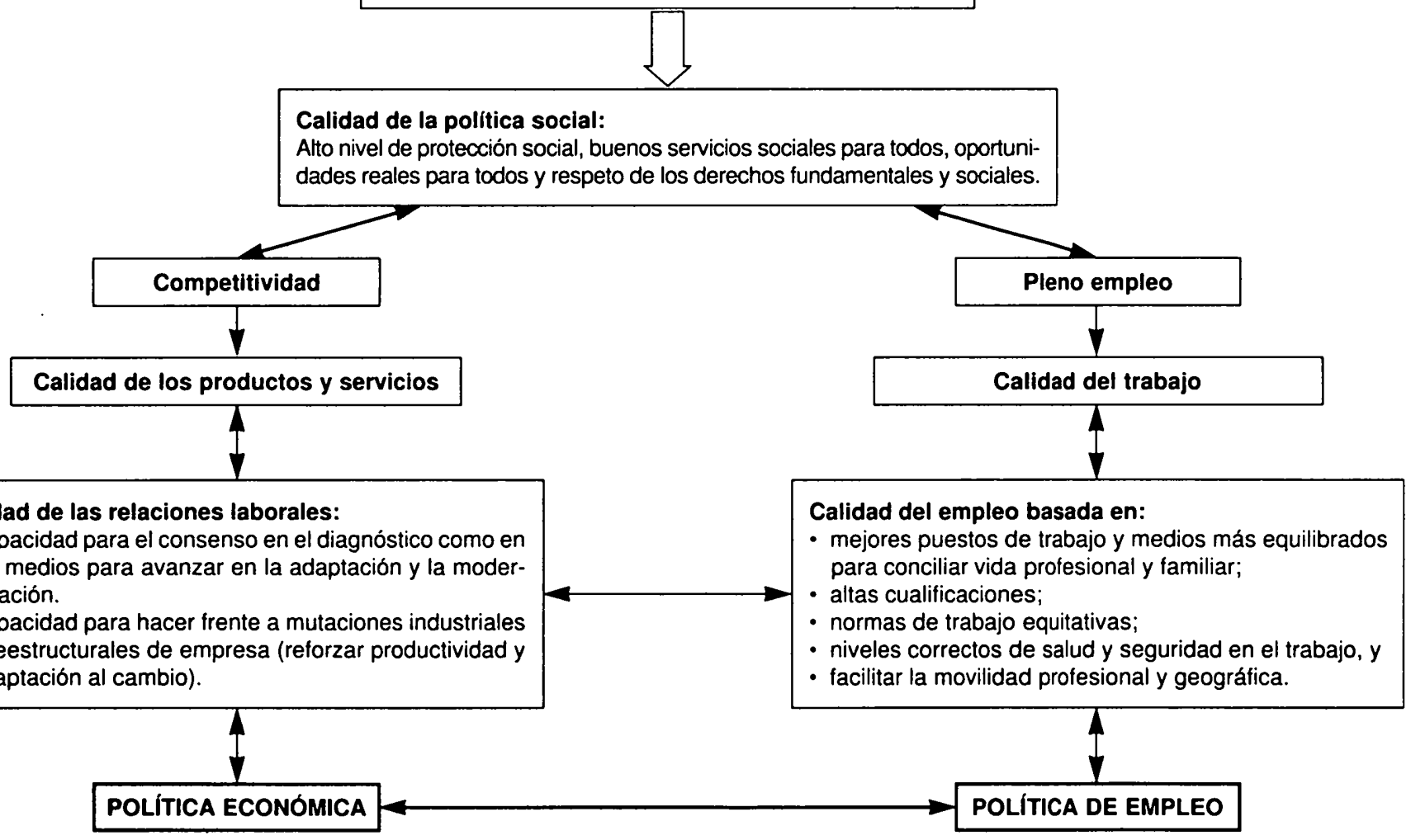

Fuente: Elaboración propia sobre la base de la Agenda de Politica Social (Comisión Europea 2000). 


\section{PLENO EMPLEO Y CALIDAD DEL TRABAJO (OBJETIVOS)}

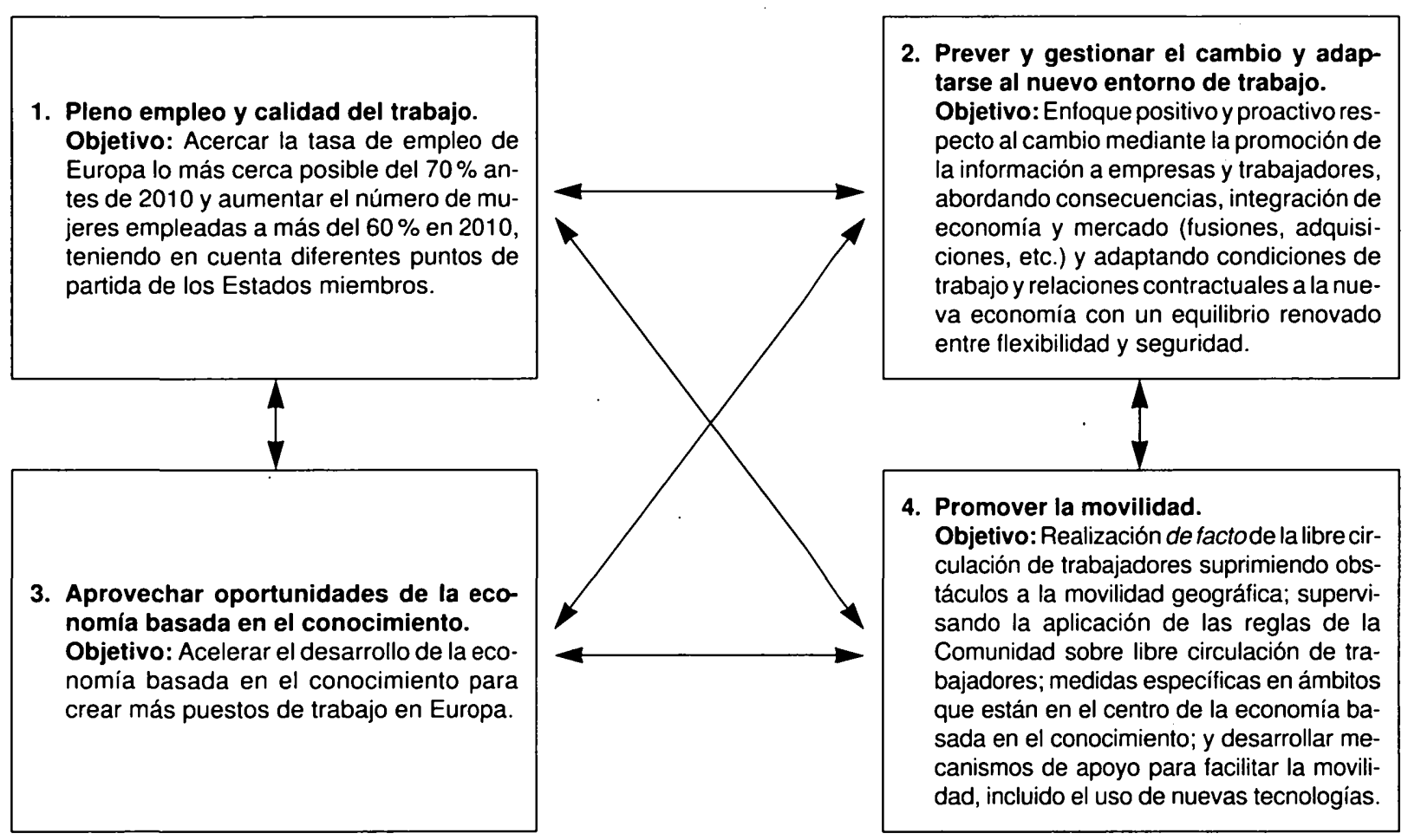

Fuente: Elaboración propia sobre la base de la Agenda de Politica Social (Comisión Europea 2000).

tica Social, es perfectamente compatible con el objetivo de participación de las personas en las organizaciones, y se define como la capacidad de basar el consenso tanto en el diagnóstico como en los medios para hacer avanzar la adaptación y la modernización; ello incluye, además, la capacidad para hacer frente con éxito a las mutaciones industriales y las reestructuraciones de empresa y, a su vez, requiere reforzar la productividad y la adaptación al cambio (ver Gráfico 8).

Como concepto integrado, la calidad de la politica social significa, también para la Agenda, un alto nivel de protección social, buenos servicios disponibles en Europa, oportunidades reales para todos y respeto de los derechos fundamentales y sociales.

Ninguno de estos atributos anteriores, relativos a la calidad del trabajo, a la calidad de las relaciones laborales o a la calidad de la política social, es incompatible con la necesaria gestión adecuada del personal o la búsqueda de la satisfacción de las personas (cliente interno), inherentes a cualquier modelo de gestión de calidad que tiene como objetivo, además, la más alta satisfacción de su cliente externo y de la sociedad en su conjunto.
La mejora de las condiciones en el entorno laboral sigue siendo objeto de interés por los investigadores sociales: se comienza a hablar de ecología social, de ecosistema corporativo, siendo el objeto de observación el individuo, así como el entorno construido por él (STEIN, 1999). Esta inquietud ha contribuido a incrementar el conocimiento de los problemas de salud relacionados con la vida laboral y con la aplicación de la legislación social (National Institute for Working Life, 2001). Así, a comienzos de 2001, tuvo lugar en Malmö (Suecia), patrocinada por la Presidencia sueca de la UE, la conferencia Work Life 2000 en la que se puso de relieve la importancia de la calidad en el trabajo. El encuentro constató que el nuevo modelo de vida laboral ha originado nuevos riesgos y problemas en el ámbito de la salud tanto psíquica como física. Además, nuestra vida laboral está cada día más interrelacionada con nuestra vida privada. No obstante, los cambios en los modelos de composición de los hogares y de la estructura familiar pueden ocasionar un aumento de las tensiones. Si se cuenta con sistemas innovadores y viables, quizá sea más fácil conciliar la vida laboral con las necesidades de las familias, los hogares y los individuos, asegurando que no sea la familia la que deba cargar con toda la responsabilidad de los cuidados de los niños y de las personas 


\section{CALIDAD DE LA POLIITICA SOCIAL Y DE LAS RELACIONES LABORALES (OBJETIVOS)}

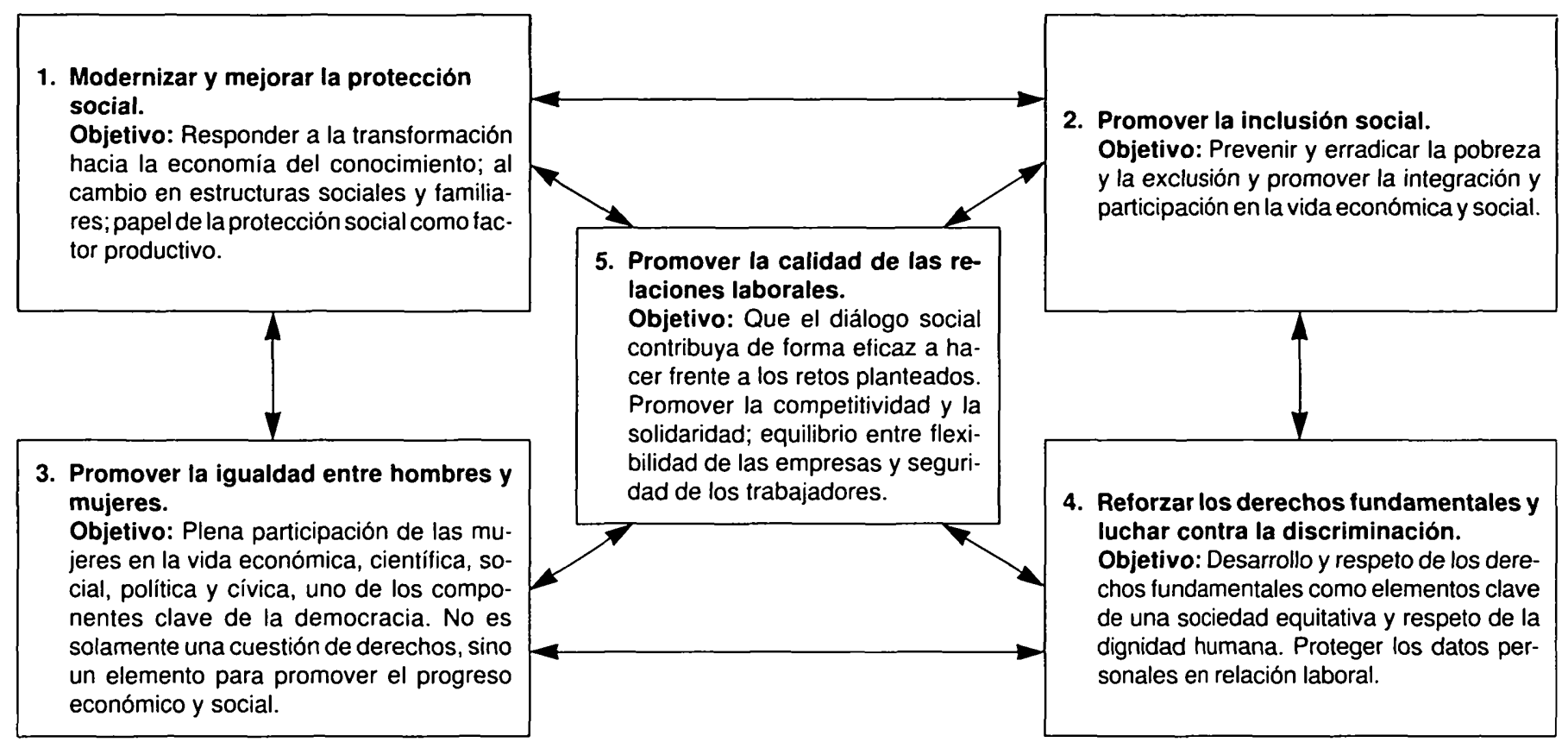

Fuente: Elaboración propia sobre la base de la Agenda Politica Social (Comisión Europea 2000).

dependientes. Además, la tendencia hacia la individualización de los derechos podría contribuir a establecer un mejor equilibrio entre los hombres y las mujeres en el mercado de trabajo y a reducir la presión sobre los sistemas de protección social (Agenda Social Europea, Niza, 2000).

Sobre todo lo apuntado, en el encuentro de Malmö se extrajeron las siguientes conclusiones:

- La diversidad en el entorno de trabajo significa sobre todo respeto de los derechos bumanos fundamentales. Debe utilizarse la competencia de todas las personas, independientemente de su sexo, raza, origen étnico, discapacidad u orientación sexual. Este aspecto es importante, asimismo, desde el punto de vista del crecimiento económico.

- Nuestra vida laboral debe ser sostenible a largo plazo y crear más y mejores empleos. Además, las condiciones de trabajo deben permitir que todas las personas tengan la posibilidad de conservar su puesto de trabajo durante un tiempo más largo que en la actualidad. Esto implica ocuparse no sólo del entorno del trabajo, sino también del desarrollo de las competencias, de la formación permanente, de la igualdad y de la responsabilidad.

- La flexibilidad de las empresas debe estar combinada con la seguridad de los trabajadores, la responsabilidad, la movilidad, la salud y el aprendizaje en el trabajo. Los trabajadores deben poder tener influencia sobre su propio trabajo, su tiempo de trabajo, así como sobre la organización y el contenido.

- Los problemas psicológicos relacionados con el trabajo, como el estrés y el agotamiento, se presentan cada día con más frecuencia, mientras que los problemas tradicionales siguen existiendo. Se debe mejorar la prevención, ya que el coste de los problemas de salud en la Unión Europea es muy elevado y su coste lo paga la sociedad, las empresas y los ciudadanos.

Finalmente, se resaltó que en el futuro será necesario motivar a las empresas a aceptar su responsabilidad en lo que concierne a la calidad del trabajo: el problema de los empresarios no es siempre la falta de recursos o de voluntad política, sino también el contar con útiles y métodos adecuados; debe verse la calidad en el trabajo como una ventaja para todos a largo plazo (National Institute for Working Life, 2001). Este enfoque sobre la mejora de la calidad en el trabajo ha sido refrendado por el Consejo Europeo de Estocolmo (2001; ver Gráfico 9).

En junio del año 2001, la Comisión Europea presentó una Comunicación relativa a las «Políticas sociales y de empleo. Un marco para invertir en calidad» [COM(2001) 313 final]. El objetivo de esta comunicación es avanzar en el compromiso de la Agenda de Política Social para promover la calidad del 
Grafico 9

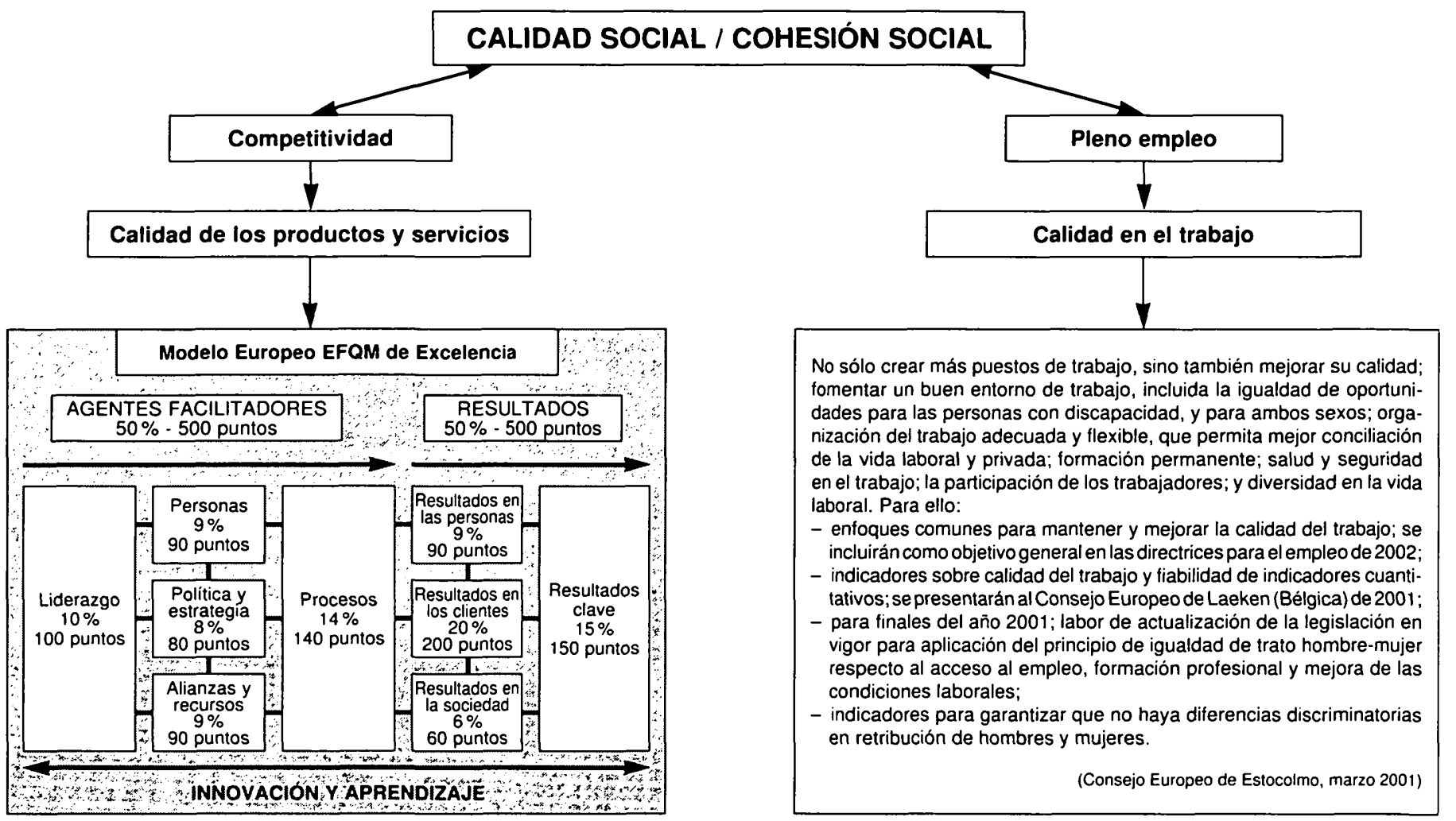

Fuente: Elaboración propia sobre la base del Modelo Europeo de Excelencia (EFQM 1999) y la Agenda Politica Social (Comisión Europea 2000).

empleo y la política social. En particular, sus actividades consistirán en:

- Definir un enfoque claro del objetivo político de mejorar la calidad del trabajo.

- Establecer un grupo coherente y amplio de indicadores de la calidad del trabajo para reforzar la eficacia y eficiencia de la política para lograr el objetivo de mejorar la calidad del trabajo.

- Asegurar de que el objetivo de mejorar la calidad se integre total y coherentemente en las políticas sociales y de empleo a través de una serie progresiva de controles de calidad.

Con el fomento de objetivos dirigidos a una calidad más elevada, y la inversión en políticas de mejor calidad, la Comisión aspira a animar y ayudar a los Estados miembros a aumentar el ritmo de mejora de la calidad de vida en la Unión, dentro y fuera del trabajo, y a ofrecer unas expectativas adecuadas a los países candidatos a la adhesión a la Unión Europea.

La Comunicación considera primero la relación entre la calidad del trabajo y la modernización del modelo social europeo. Considera cómo definir la calidad y pasa luego a considerar la elaboración de indicadores de la calidad del trabajo. Finalmente, se centra en la aplicación y la utilización de estas defi- niciones y estos indicadores por medio de un proceso de controles de calidad.

\section{El modelo europeo de excelencia (EFQM) y la calidad social}

\subsection{Equilibrio entre Agentes y Resultados}

La Gestión de la Calidad Total - Total Quality Management, $T Q M$ - es una forma de gestionar las organizaciones que tiene como objetivo la satisfacción de sus empleados, los clientes, las organizaciones relacionadas y la sociedad en general. Este enfoque tiene su referente en el Modelo Europeo de Excelencia de la Fundación Europea para la Gestión de la Calidad - European Foundation for Quality Management, EFQM-, así como en las normas ISO 9000, a las que hemos hecho referencia en páginas anteriores. 
Las normas ISO 9000 surgen al final de la década de los ochenta en el ámbito industrial como una serie de requisitos que aseguran la calidad de un producto. Éstas constituyen una guía con unos pasos y acciones perfectamente establecidas que permiten alcanzar la conformidad de una producción a unas especificaciones de calidad. Entre sus principales ventajas destacan que son unas normas conocidas internacionalmente y que se pueden adaptar a cualquier organización.

¿Por qué se ha elegido el Modelo Europeo de Excelencia EFQM para aplicarlo a la calidad social? Las investigaciones actuales sobre la aplicación de modelos de calidad sugieren que no hay un modelo único que sea el más adecuado para todas las circunstancias. Además, entre los modelos a elegir, éstos deberían ser fruto de una amplia investigación empírica, ser susceptibles de aplicación y tener una larga tradición en el entorno europeo. De esta forma tratamos de asegurar la adopción de un modelo consistente, asentado en una cultura con valores europeos y que fuera un método robusto y comúnmente aceptado (más de 10.000 organizaciones privadas y públicas de toda Europa han incorporado el modelo de la EFQM en su gestión corporativa). Entendemos que el Modelo Europeo de Excelencia contiene todos los atributos mencionados. Además, la EFQM tiene como objetivo reforzar la posición de las organizaciones europeas en el mercado mundial a través de los siguientes valores: alcanzar la excelencia en la organización; orientación al cliente; valoración del personal; respeto por la sociedad, y actuar con integridad (MarCos Hernández, 2000). Por ser suficientemente conocido, sólo se señalan a continuación las formulaciones generales que se contemplan en el nuevo Modelo EFQM de 1999.

El Modelo Europeo de Excelencia de la EFQM permite la evaluación y comparación entre sistemas similares. En tanto que inspirado en la filosofía de la Calidad Total, responde a una concepción más global de la evaluación e incluye nueve criterios, cada uno de los cuales tiene asignado un porcentaje en su contribución al éxito del sistema (ver Gráfico 9). Un aspecto a matizar es que el Modelo Europeo tiene por objetivo la identificación de los puntos fuertes y débiles de un sistema para la elaboración de programas de mejora continua. Permite identificar las mejores prácticas y, en base a sus criterios, concede un Premio Europeo a la Calidad.

El Modelo EFQM se asemeja bastante a un holograma. Cada uno de los criterios: Agentes (Liderazgo, Gestión del Personal, Política y Estrategia, Alianza y Recursos), Procesos y Resultados clave de actuación (Satisfacción de las Personas, de los Clientes e Impacto en la Sociedad), contiene de alguna manera a los demás (Morales Delgado, 1999). El Modelo Europeo EFQM se basa en el necesario equilibrio entre las dos partes importantes para conseguir la excelencia: los Agentes facilitadores y los Resultados, dando a cada conjunto de criterios la misma puntuación. $O$ expresado de otra manera: no vale con hacer muchas cosas, o el virtuosismo en cómo se ejecutan, si no se consiguen resultados. Como tampoco valen unos resultados que no sean la consecuencia de unas acciones planificadas, sistemáticas, evaluadas y mejoradas. Es en este punto donde el modelo cobra una especial relevancia (BABÉ ROMERO, 1999).

\subsection{La importancia de las personas}

El Modelo Europeo de Excelencia que no es prescriptivo $y$, por tanto, no contiene recetas sino ingredientes, supone una esquematización de la forma de gestionar una organización para conseguir la excelencia. Pero, además del valor que tiene cada uno de los nueve criterios del modelo por sí mismo, éste contiene numerosos valores relacionados con las personas. Entre ellos destacan los siguientes:

- enfatiza el desarrollo profesional para todos los empleados;

- orienta a la organización para que trate a su personal con dignidad, respeto y confianza;

- ofrece posibilidades de participación en la gestión a los implicados en los procesos (mejoras) y promueve la adopción de decisiones en los niveles operativos de la organización (autocontrol);

- estimula el trabajo en equipo y la comunicación en todos los sentidos;

- favorece la innovación, la creatividad y el conocimiento a todos los niveles en la organización;

- exige la recogida de información directa sobre el nivel de satisfacción de los empleados, y

- recomienda asociar los planes de acción con resultados concretos y la oportunidad de comunicar ambos.

El Modelo, además, incluye dos criterios relativos al personal: Gestión del Personal y Satisfacción del Personal, cuyas ponderaciones sumadas $(90+90=180)$ convierten a los empleados en los segundos protagonistas más importantes tras los clientes (ponderación 200), del Modelo de Excelencia. Si a esto añadimos que el Liderazgo lo desarrollan empleados (directivos) para otras personas (empleados, proveedores, clientes, etc.); que la Política y Estrategia la definen empleados para que otros, o los mismos empleados, las desarrollen; que la gestión de los Recursos la hacen, generalmente, empleados; que uno de los componentes más importantes en la gestión de los Procesos son las personas/empleados de la organización, nos encontramos con que realmente las personas son el componente más importante del Modelo Europeo de Excelencia (BABÉ ROMERO, 1999).

Considerar el factor humano como el mejor activo con que cuenta la sociedad se ha convertido también en un tópico de nuestra retórica contemporánea. En un esfuerzo de identifi- 
cación de los atributos que configuran la calidad social con las estrategias de calidad aplicadas a productos y servicios, estas últimas reconocen que el recurso más importante con el que cuentan las organizaciones es el capital humano. Ello requiere articular esquemas de motivación y reconocimiento de las personas, de forma que toda su iniciativa y creatividad sea aprovechable. Ahora bien, el reconocimiento no puede basarse únicamente en la compensación económica (satisfacción) ya que la mayoría de las personas buscan otro tipo de reconocimientos: seguridad en el trabajo, integración social, autoestima y autorrealización (motivación).

Nada de lo anteriormente señalado es ajeno a los principios formulados por la Agenda de Política Social. Tanto la calidad del trabajo como la calidad de las relaciones laborales, sitúa a las personas en el centro de las preocupaciones sociales, en el activo más importante de la UE:

- garantizando el desarrollo y el respeto a los derechos sociales fundamentales como elementos clave de una sociedad equitativa;

- protegiendo los datos personales en la relación laboral;

- promoviendo la igualdad de género;

- desarrollando un enfoque positivo y proactivo respecto al cambio, mediante la información adecuada a empresas y trabajadores;

- adaptando las condiciones de trabajo y las relaciones contractuales a la nueva economía a fin de favorecer el equilibrio entre flexibilidad y seguridad;

- aprovechando las oportunidades de la economía basada en el conocimiento, con una educación y una formación de las personas a lo largo de toda su vida.

Este último comentario nos conduce a considerar otro de los aspectos cruciales de toda estrategia de calidad: la formación de las personas. A través de los procesos de aprendizaje, las personas aprecian que sus ideas son escuchadas y rentabilizadas, sintiéndose parte integrante en el proceso de modernización de su organización e identificados con sus objetivos estratégicos. Podemos extrapolar esta necesidad de formación a nivel organizacional con las necesidades identificadas en la Agenda, desde un planteamiento estratégico más amplio.

En efecto, el desarrollo de los recursos humanos, en particular la mejora de las cualificaciones, y la generalización de la formación permanente son cruciales en la sociedad del conocimiento. Asimismo, la igualdad de acceso a la educación y a la formación, y la calidad de éstas son de la mayor importancia para brindar a las personas auténticas oportunidades que les permitan adaptarse a unas condiciones de trabajo en rápido cambio y a las necesidades de una economía y una sociedad basadas en el conocimiento (iniciativa comunitaria y plan de acción e-Europe: garantizar que la Unión se beneficie de las tecnologías digitales, desarrolle las cualificaciones necesarias, propicie medidas para fomentar el uso de Internet), y que la nueva sociedad de la información sea socialmente integradora (Consejo Europeo de Estocolmo, marzo de 2001).

\subsection{Política y Estrategia}

El Modelo Europeo de Calidad de la EFQM ofrece en su criterio 2, Política y Estrategia, el elemento articulador de todo el Modelo. Esta articulación debe producirse desde la creación de un sistema de afloración y generación del conocimiento colectivo que culmine con la concreción de las metas estratégicas cuantificables, se despliegue mediante una gestión de los procesos y sirva de base para los planes de acción. Todo ello está orientado hacia la consecución de la excelencia, pero no como un concepto abstracto, sino como la traducción en una mejora de la capacidad competitiva de las organizaciones. El término organización debe interpretarse en el sentido más amplio, incluyendo también las organizaciones sin ánimo de lucro y aquellas en las que su razón de ser no se apoye en el beneficio ni en su necesidad de supervivencia en un sistema de mercado (Tolosa, 2001). Esto refuerza, además, el punto de vista ético (ver apartado 2.1) como parte fundamental del Modelo Europeo de Excelencia y el papel de las organizaciones públicas europeas en cuanto a la calidad de los servicios que prestan a sus usuarios y a la sociedad en su conjunto.

La Cumbre de Jefes de Estado y de Gobierno, celebrada en Lisboa (marzo de 2000), definió para la Unión Europea un objetivo estratégico sumamente ambicioso, aunque pragmático, que consiste en llegar a ser en el año 2010 la economía basada en el conocimiento más competitiva y dinámica del mundo, capaz de crecer económicamente de manera sostenible, con más y mejores empleos y con mayor cobesión social. En Lisboa los líderes europeos recordaron, además, que el modelo social europeo, con sus sistemas desarrollados de protección social, debe apuntalar el tránsito a la economía basada en el conocimiento. Asimismo, los Estados miembros subrayaron que la inversión en capital humano y el fomento de un Estado de bienestar activo y dinámico serán esenciales tanto para que Europa ocupe un lugar en la economía basada en el conocimiento como para garantizar que el surgimiento de esta nueva economía no incremente los problemas sociales existentes de desempleo, exclusión social y pobreza.

Por su parte, la Cumbre de Niza (diciembre de 2000), como se ha señalado reiteradamente, aprueba la Agenda Social Europea en torno a seis orientaciones estratégicas:

- por un mayor número y una mejor calidad de los puestos de trabajo;

- anticiparse a los cambios del entorno laboral y sacar partido de los mismos desarrollando un nuevo equilibrio entre flexibilidad $y$ seguridad; 
- luchar contra cualquier forma de exclusión y de discriminación para favorecer la integración social;

- modemizar la protección social;

- fomentar la igualdad entre el bombre y la mujer, y

- reforzar la dimensión social de la ampliación y de las relaciones exteriores de la Unión Europea.

Estos objetivos ofrecen una visión clara de la situación en cuanto a las medidas a adoptar para reforzar la calidad del trabajo, de la política social y de las relaciones laborales (Cuadro de mando sobre la aplicación de la Agenda de Política Social, Comisión 2001). Como señala la Comisión en sus objetivos estratégicos para el período 2000-2005, los retos son múltiples: asistimos a una transformación fundamental de la economía y de la sociedad; la globalización disuelve las fronteras tradicionales; la revolución digital transforma nuestra manera de comunicarnos y de relacionarnos. Los asuntos internacionales exigen, cada vez más, respuestas globales. Son retos demasiado grandes y complejos para cualquier país aislado, y por eso la necesidad de una respuesta colectiva europea nunca ha sido tan evidente. El mundo se vuelve hacia Europa en busca de un liderazgo imbuido de principios, y nuestros ciudadanos también piden una acción europea eficaz, una acción guiada por los valores europeos que compartimos y que refuerce la esencia de nuestra identidad europea (Comisión 2000).

\subsection{Procesos: Luxemburgo, Cardiff y Colonia}

El criterio 5 del Modelo Europeo de Excelencia se refiere a cómo diseña, gestiona y mejora cualquier organización sus procesos para apoyar su política y estrategia, y para satisfacer plenamente, generando cada vez mayor valor, a sus clientes y otros grupos de interés. Las organizaciones alcanzan resultados más eficientes cuando se comprenden todas las actividades que están interrelacionadas y se gestionan de forma sistemática. Las decisiones sobre procesos actuales o mejoras planificadas se deben llevar a cabo, usando información fiable que además incluya impresiones de los grupos de interés. Los beneficios que permite alcanzar son la orientación hacia resultados deseados, la optimización del uso de personas y recursos, la consistencia en los resultados y de control de las desviaciones; gestión basada en hechos para establecer una dirección en la estrategia con objetivos realistas.

Una aplicación al entorno comunitario nos lleva a destacar tres procesos fundamentales para la puesta en práctica de las decisiones en la UE en el ámbito económico-social: los procesos de Luxemburgo, Cardiff y Colonia. En cuanto al primero, el Consejo Europeo Extraordinario sobre el Empleo, celebrado en Luxemburgo a finales de 1997, inició una estrategia global para el empleo, la Estrategia Europea de Empleo, que incluye la coordinación de las políticas de empleo de los Estados miem- bros basándose en las directrices para el empleo acordadas en común (el proceso de Luxemburgo), la continuación y el desarro. llo de una política macroeconómica coordinada y un mercado interior eficaz, que siente las bases de un crecimiento sostenible, un nuevo dinamismo y un clima de confianza favorable a la reactivación del empleo. Esta estrategia incluye también una movilización más sistemática del conjunto de las políticas comunitarias al servicio del empleo, tanto si se trata de políticas marco como de políticas de apoyo. Comporta un informe conjunto, unas orientaciones y unas recomendaciones sobre empleo (Título VIII del Tratado de la Comunidad Europea).

El llamado proceso de Cardiff (Reino Unido), iniciado en el Consejo Europeo celebrado en dicha ciudad a mediados del año 1998, puso en marcha un procedimiento de coordinación de las reformas estructurales en los mercados de bienes y servicios, y de capitales. El proceso de Cardiff, complementario del Pacto de Estabilidad y Crecimiento y del control multilateral de los Planes Nacionales de Acción para el Empleo, es un examen sin obligaciones jurídicas cuya eficacia se basa en la presión que se ejerce sobre los Estados miembros (peer pressure) y en la puesta en común de las mejores prácticas (best practices). Se trata así de que las experiencias positivas realizadas en un Estado miembro sean seguidas en la medida de lo posible por el resto (Jiménez LatorRe y Romana García, 2000). Estos mismos autores señalan la persistencia de asimetrías a ambos lados del Atlántico en términos de rentabilidad, oportunidades de inversión y flujos de capital, lo que se refleja en la debilidad del euro y la fortaleza del dólar. Conscientes de estas diferencias, la Cumbre extraordinaria de Lisboa adquirió un compromiso político, al más alto nivel, para la apertura y liberalización de los mercados de bienes, servicios y capitales, introduciendo una serie de objetivos y calendarios concretos y estableciendo un procedimiento de vigilancia de su grado de cumplimiento.

Para el seguimiento del grado de cumplimiento de estos ambiciosos objetivos, el Consejo de Lisboa decidió que antes de finalizar el año 2000 se establecieran unos indicadores cuantitativos de reforma estructural y en la primavera de cada año se celebrará un Consejo Europeo monográfico sobre la evolución de las reformas (Consejos de Estocolmo -2001- y Barcelona -2002-). La garantía de cumplimiento de estos objetivos se basa en la presión que colectivamente se hará sobre los Estados miembros a partir de la evolución de los indicadores que se establezcan (ver apartado 4).

Finalmente, el Consejo Europeo de Colonia (Alemania), de junio de 1999, dió lugar al llamado Proceso de Diálogo Macroeconómico, mediante reuniones periódicas de los Ministros de Economía y Finanzas y de los Ministros de Trabajo y Asuntos Sociales, con representantes de los sindicatos europeos, de los empresarios europeos, de la pequeña y mediana empresa, de la Comisión y del Banco Central Europeo. Se trata de explicar 
y compartir la política macroeconómica, de empleo y de reformas estructurales a escala europea. Desde entonces, en reuniones periódicas de este foro de debate, tanto a nivel de expertos como a nivel de ministros, se explica y se comparte la política económica de la Unión Europea para que sea asumida por todos los actores.

\subsection{Impacto en la sociedad}

En el marco del Modelo EFQM de Excelencia, el criterio de resultados de los clientes se refiere específicamente a los logros de la organización en relación con la satisfacción de sus clientes externos. No es una casualidad que el criterio de resultados de clientes sea el que recibe el mayor peso relativo entre los nueve criterios que componen el Modelo EFQM de Excelencia (200 puntos o el $20 \%$ ). El factor «cliente» es un factor crítico en la visión de cualquier organización excelente. Por regla general, las empresas que diseñan sus procesos con una fuerte orientación al cliente, es decir, basándose en la necesidad de alcanzar niveles elevados de satisfacción de sus clientes, ven cómo sus resultados finales están íntimamente relacionados con dicho logro (ROuRE, 2000).

Como señaló el Consejo Europeo de Lisboa, las personas constituyen en Europa el principal activo, por lo que deberían convertirse en el centro de las políticas de la Unión. Por tanto, es legítimo considerar que los 375 millones de ciudadanos europeos constituyen el público objetivo de las políticas de la UE. Siguiendo la definición de calidad de DEMING, apuntaba al principio de este trabajo, desde una perspectiva integrada de satisfacción social, se trataría de buscar, a través de la calidad social, la satisfacción plena de la sociedad europea.

El Tratado de Amsterdam (art. 16) introdujo una referencia a la función de los servicios de interés general (este concepto abarca los servicios de mercado y no mercado que las autoridades públicas consideran de interés general y a los que imponen determinadas obligaciones de servicio público - Comisión Europea, 2001-). El nuevo artículo 16 del Tratado CE reconoce el carácter fundamental de los valores subyacentes a estos servicios y la necesidad de que la Comunidad Europea tenga en cuenta su función en la concepción y aplicación de todas sus políticas.

La declaración del Consejo Europeo de Niza (2000) sobre los servicios de interés económico general (basada en la Comunicación de la Comisión Los servicios de interés general en Europa, 2001) señala que, en nuestras economías abiertas a la competencia, estos servicios desempeñan un papel irreemplazable para garantizar la competitividad global de la economía europea, que se ha hecho atractiva por la calidad de sus infraestructuras, el alto grado de formación de los trabajadores, el refuerzo y el desarrollo de redes en el conjunto del territorio, y para acom- pañar los actuales cambios. En este contexto, la nueva comunicación revisada de la Comisión sobre los servicios de interés general recibía una acogida positiva, en particular, debido, entre otros, a los siguientes puntos:

- la contribución de los servicios de interés económico general a la competitividad europea responde a objetivos propios: protección de los intereses del consumidor, seguridad de los usuarios, cohesión social y ordenación territorial, y desarrollo sostenible;

- el desempeño del cometido de los servicios de interés económico general debe efectuarse en el respeto de las expectativas legítimas de los consumidores y de los ciudadanos, que desean obtener precios asequibles en un sistema transparente de precios, y que quieren un acceso igual a servicios de calidad, indispensables a su inserción económica, territorial y social;

- la contribución de los servicios de interés económico general al crecimiento económico y al bienestar social justifican plenamente una evaluación regular de cómo se llevan a cabo sus funciones, en particular, en términos de calidad del servicio, de accesibilidad, de seguridad y de precio equitativo y transparente. Esta evaluación podría efectuarse en el marco del proceso de Cardiff (ver apartado 3.4). La consulta de los ciudadanos y los consumidores podría hacerse, asimismo, a través del foro El mercado interior al servicio de los ciudadanos y de las empresas.

Desde una perspectiva social, el reciente informe Los servicios sociales públicos: calidad de vida profesional y calidad del servicio, de la Fundación Europea para la Mejora de las Condiciones de Vida y de Trabajo (Dublín, 2001), presenta una síntesis de los resultados de una investigación realizada en los Estados miembros de la UE. El informe constata un importante proceso de mejora de la calidad de las prestaciones suministradas por los servicios públicos sociales, tanto a nivel nacional como local. Cada vez se considera más relevante aplicar indicadores de buena calidad, definir los derechos de los usuarios (carta de servicios) y las condiciones de trabajo de los empleados, que permitan establecer reglas que aseguren un nivel de calidad a los prestatarios de los servicios cada vez más diversificados. Los mecanismos que aseguran la calidad, continúa el informe, así como la evaluación y la redefinición de la planificación de los servicios han sido introducidos con éxito; sobre todo cuando los trabajadores han participado en la redefinición de las prestaciones y la forma de suministrarlas, cuando se ha trabajado en equipo, $y$, en definitiva, cuando los métodos de management han sido utilizados de manera flexible.

A mediados del año 2000, la Confederación Europea de Sindicatos (CES) y el Centro Europeo de la Empresa Pública (CEEP) propusieron al Consejo (Presidencia portuguesa) una Carta de Servicios de Interés General, que constituye una interesante contribución al actual debate sobre el futuro de estos servicios (de momento, sólo es un proyecto no asumido por 
el Consejo). Su objetivo es establecer un marco de referencia con los principios que dan contenido a la noción de valor común de dichos servicios generales, afirmado en el artículo $16 \mathrm{del}$ TCE, y contribuir a la estrategia definida en la Cumbre de Lisboa. Incluso, los patrocinadores de la Carta proponen que ésta sea añadida al texto del Tratado de la UE en forma de protocolo (ver Gráfico 10).

\subsection{Alianzas y Recursos}

En paralelo con el concepto de cliente, el Modelo Europeo de Calidad de la EFQM incorpora también un concepto ampliado de proveedor, entendido éste como aquellas personas, instituciones u organizaciones que suministran productos, servicios o conocimiento a la organización, es decir, no sólo el proveedor externo a la organización, sino también sus trabajadores, los cuales dentro de la cadena de producción o de prestación del servicio son proveedores y clientes los unos de los otros. El modelo propugna unas relaciones con los proveedores basadas en la confianza y en la integración, generando con ello mejoras y valor añadido a clientes y proveedores.

Obviamente, la búsqueda de alianzas estratégicas no es sino un modo de establecer relaciones. Siguiendo a CARDELL y JOHN. SON (2000), podemos diferenciar las actividades que pueden externalizarse (cuando queremos gestionar costes), de las susceptibles de firma de alianzas (cuando queremos obtener valor). Para el objetivo de este trabajo, nos quedamos con las acti- vidades candidatas a las firmas de alianzas, como aquellas en que el proveedor incide de manera directa en las prioridades estratégicas planeadas y donde la confianza mutua y el conocimiento que requiere el proveedor para aportar su valor real al cliente no puede sustituirse con facilidad. Las alianzas son herramientas estratégicas basadas en tres principios:

- los participantes en la alianza han de seguir siendo autónomos y pueden no coincidir en los objetivos;

- en una alianza estratégica ninguno de los partenaires puede tener una posición dominante;

- los partenaires deben realizar aportaciones iguales y continuas a la alianza (Club Gestión de Calidad, 2000).

La identificación con la Agenda Social Europea (Niza, 2000) podría contemplar los siguientes elementos:

- Alianzas: todos los agentes tienen un papel a desempeñar, Instituciones de la Unión Europa (Parlamento Europeo, Consejo, Comisión), Estados miembros, autoridades regionales y locales, los interlocutores sociales, la sociedad civil y las empresas.

- Recursos (modalidades de aplicación): para su aplicación, la Agenda Social deberá recurrir, sin practicar ninguna exclusión, a toda la gama de instrumentos comunitarios existentes, el método abierto de coordinación; la legislación (también la que se base en acuerdos con interlocutores sociales); el diálogo social; los Fondos Estructurales (especialmente el Fondo Social Europeo); los programas de apoyo; el planteamiento integral de las políticas, y el análisis y la investigación.

\section{PROYECTO DE “CARTA DE SERVICIOS” DE INTERÉS GENERAL}

Principios:
- Construir una UE equilibrada integrando dimensión social en procesos de decisión económica.
- Garantizar derechos fundamentales de los ciudadanos: la Carta de Derechos Fundamentales de la Unión
- Auropea (diciembre 2000).
- Reforzar solidaridad y lucha contra la exclusión.
- Apoyar desarrollo económico y empleo.
- Reforzar cohesión social y territorial.
- Asociar ciudadanos a evaluación de servicios de interés general.
- Asegurormación, la consulta y la participación de los trabajadores y de sus representantes son esenciales.
- Señalar responsabilidad fundamental de autoridades públicas.
- Marco para la gestión contractual y transparente de los servicios de interés general.
- Acompañar adhesión de países candidatos.
- En definitiva, construir con la Carta de Servicios de Interés General el marco de referencia de un valor co-
mún de Unión Europea.


El Gráfico 11 contempla el proyecto de aplicación, realizado por el autor de este trabajo, del Modelo Europeo de Excelencia de la EFQM, a los conceptos de calidad social contenidos en la Agenda Social Europea, aprobada en el Consejo Europeo de Niza, a finales del 2000 (basada en la Agenda de Política Social presentada por la Comisión en junio del mismo año), así como aquellos documentos estratégicos comunitarios surgidos a raíz de la Cumbre de Lisboa.

\section{Medir la calidad social: los indicadores estructurales}

Es habitual en las estrategias de calidad el reconocimiento de que si ésta no puede ser medida, no puede ser comprendida; si no puede ser comprendida, no puede ser controlada, y si no puede ser controlada, no puede ser mejorada (Howard S. SmLow). Es por ello que cualquier documentación de soporte a un sistema de calidad contenga los indicadores de calidad. Éstos se definen como un valor que permite comprobar el grado de cumplimiento de un estándar de calidad (condiciones que han de cumplir los productos o servicios para que tengan la calidad demandada).

Para los responsables de implantación de estrategias de calidad, cada vez resulta más evidente contar con un sistema de indicadores con alto grado de fiabilidad, que permita la elaboración de un sistema integrado de evaluación. Los sistemas de indicadores están formados por un conjunto integrado de éstos, para los que se habrán definido jerarquías y relaciones, así como el mecanismo de diseño y revisión. Este sistema integrará indicadores que van a suministrar información sobre la actuación pasada, con otros de aviso y actuación rápida, como los de satisfacción de las personas (HERAS FORCADA, 1999).

La Comunidad no ha estado ajena a esta tendencia. La experiencia acumulada en los últimos años indica la propensión a cuantificar los esfuerzos políticos y los resultados económicos en el seno de la Unión Europea. Así, la Cumbre de Lisboa hizo referencia a que las mejoras estructurales son esenciales a la hora de alcanzar los objetivos de crecimiento, empleo e integración social y que se deben definir una serie de indicadores de resultado estructurales en cuatro campos de acción: el empleo, la innovación, la reforma económica y la cohesión social (ver Gráfico 12; Comunicación Comisión sobre Indicadores Estructurales, 2000).

No obstante, si se ha de contar con unos indicadores, éstos han de ser homogéneos a nivel comunitario, de tal modo que puedan establecer comparaciones adecuadas entre los diversos Estados miembros y a lo largo de los años:
- Por lo que se refiere a los indicadores de empleo, éstos son los habituales para medir la creación de empleo, los niveles de desempleo y la incidencia en los grupos más vulnerables del mercado de trabajo. Especial mención merece el indicador relativo a la formación permanente (participación de los adultos en la educación y la formación) que requiere una mayor profundización para permitir la comparabilidad a nivel europeo (el Comité de Empleo del Consejo ya está trabajando en este sentido).

- En este contexto la Agenda Social Europea señala que hay que tener más en cuenta los objetivos relacionados con la calidad del empleo y con su importancia para el crecimiento como elemento importante de atracción e incitación al trabajo. Una comunicación de la Comisión en el 2001 tratará sobre la aportación de la política de empleo a la calidad del empleo en sus diversos aspectos (especialmente en lo que se refiere a las condiciones de trabajo, la salud y la seguridad, la remuneración, la igualdad de sexos, el equilibrio entre la flexibilidad y la seguridad, y las relaciones sociales). Sobre esta base, el Comité de Empleo presentará un informe sobre la cuestión, a finales de 2001, para que se puedan definir unos indicadores que permitan seguir de cerca todo lo indicado anteriormente.

En cuanto a los indicadores de cobesión social cabe hacer las siguientes observaciones:

- la ausencia de indicadores sociales homogéneos y consensuados sobre exclusión social y pobreza sigue siendo uno de los retos pendientes en la UE;

- los indicadores en los EEMM, en esta materia, son básicamente unidimensionales y ligados a la distribución de recursos, $y$

- están afectados por problemas en las fuentes de información y suponen una difícil armonización entre los EEMM de la UE.

En este sentido, el Comité de Protección Social del Consejo ha comenzado sus trabajos, en el año 2001, creando un grupo específico sobre indicadores, esperándose los primeros resultados para finales del mismo año. Por su parte, el Comité de Política Económica está profundizando en los indicadores de índole económica (ver Gráfico 12).

\section{Una conclusión asertiva}

No cabe duda de que asistimos a un nuevo paradigma, un nuevo patrón de medida para entender y comprender la realidad social que nos ha tocado vivir. La introducción de nuevas tecnologías siempre ha tenido como resultado cambios sociales. La diferencia reside, esta vez, en que mientras la tecnología ha avanzado vertiginosamente, los cambios sociales no han 


\section{PROYECTO DE APLICACIÓN DEL MODELO EUROPEO DE EXCELENCIA (EFQM) A LA “CALIDAD SOCIAL” (UE)}

Las personas, el activo más importante de la UE:

- garantizando el desarrolio y el respeto a los derechos sociales fundamentales;

- protegiendo los datos personales en la relación laboral;

- promoviendo la igualdad de género;

- desarrollando un enfoque positivo y proactivo para el cambio;

- adaptando las relaciones de trabajo y las relaciones contractuales a la nueva economia;

- aprovechando las oportunidades de la economia basada en el conocimiento.

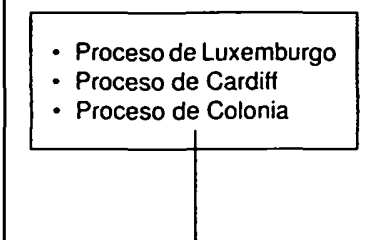

Agenda Social Europea, seis orientaciones estratégicas:

- mayor número y mejor calidad de los puestos de trabajo;

- anticiparse a los cambios del entorno laboral y sacar partido de los mismos desarrollando un nuevo equilibrio entre flexibilidad y seguridad;

- luchar contra cualquier forma de exclusión y de discriminación para favorecer la integración social;

- modernizar la integración social;

- fomentar la igualdad entre el hombre y la mujer;

- reforzar la dimensión social de la ampliación y de las rela. ciones exteriores de Unión Europea (Consejo Europeo Niza).

\section{- Consejo Europeo
- Consejos de Ministros
ECOFIN y Empleo y Politica
Social
- Comisión
- Parlamento Europeo
- Estados miembros}

Nuevo objetivo estratégico de la UE: convertirse en economia basada en el conocimiento más competitiva y dinámica del mundo, capaz de crecer económica. mente de manera sostenible y con más y mejores empleos y con mayor cohesión social (Consejo Europeo Lisboa).

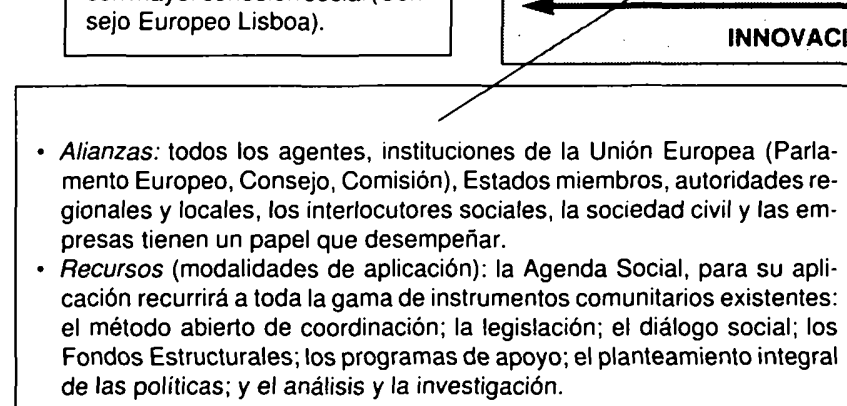

podido seguir el mismo ritmo. De hecho, existe una distancia cada vez mayor entre el cambio social y el cambio tecnológico. La comprensión de estos fenómenos sociales nos puede ayudar a entender cómo solucionar, como señala NAISBITT (1998), la tensión creativa entre la alta tecnología (bigh tech) y el alto contacto humano (bigh touch). Ello implica defender una nueva visión a través de la calidad social, una restauración de la relación entre la política económica y la política social, sin que prevalezca una sobre otra, conviviendo en equilibrio.

Los que desde hace varias décadas somos observadores de la trayectoria de la unificación europea sabemos que los avances en la Comunidad se asemejan, a veces, a los trabajos de Sísifo: empujar constantemente una piedra hacia la cumbre, que vuelve a caer cuando está a punto de llegar a la cima. Frente a aquellos investigadores sociales que no están satisfechos con la trayec- toria actual del proyecto europeo en el plano social, el autor de estas páginas, aun compartiendo este criterio, prefiere un punto de vista más asertivo, de afirmación en lo positivo, y más posibilista.

Conviene reconocer que después del Tratado de Amsterdam, lo social ha dejado de ser un invitado de segunda categoría en la UE. Tras un largo proceso de recuperación de la confianza de los europeos a lo largo de los años noventa, el Tratado de Amsterdam logra dar un paso importante hacia una Europa más social: nuevo Título VIII de Empleo y nacimiento de la Estrategia Europea de Empleo, principal reto y preocupación de la ciudadanía europea. En cuanto a la protección social, hace unos años hubiera sido impensable vaticinar que el debate sobre la seguridad social, que se encontraba en el entorno nacional, pasaría al ámbito comunitario. En menos de un año, se 


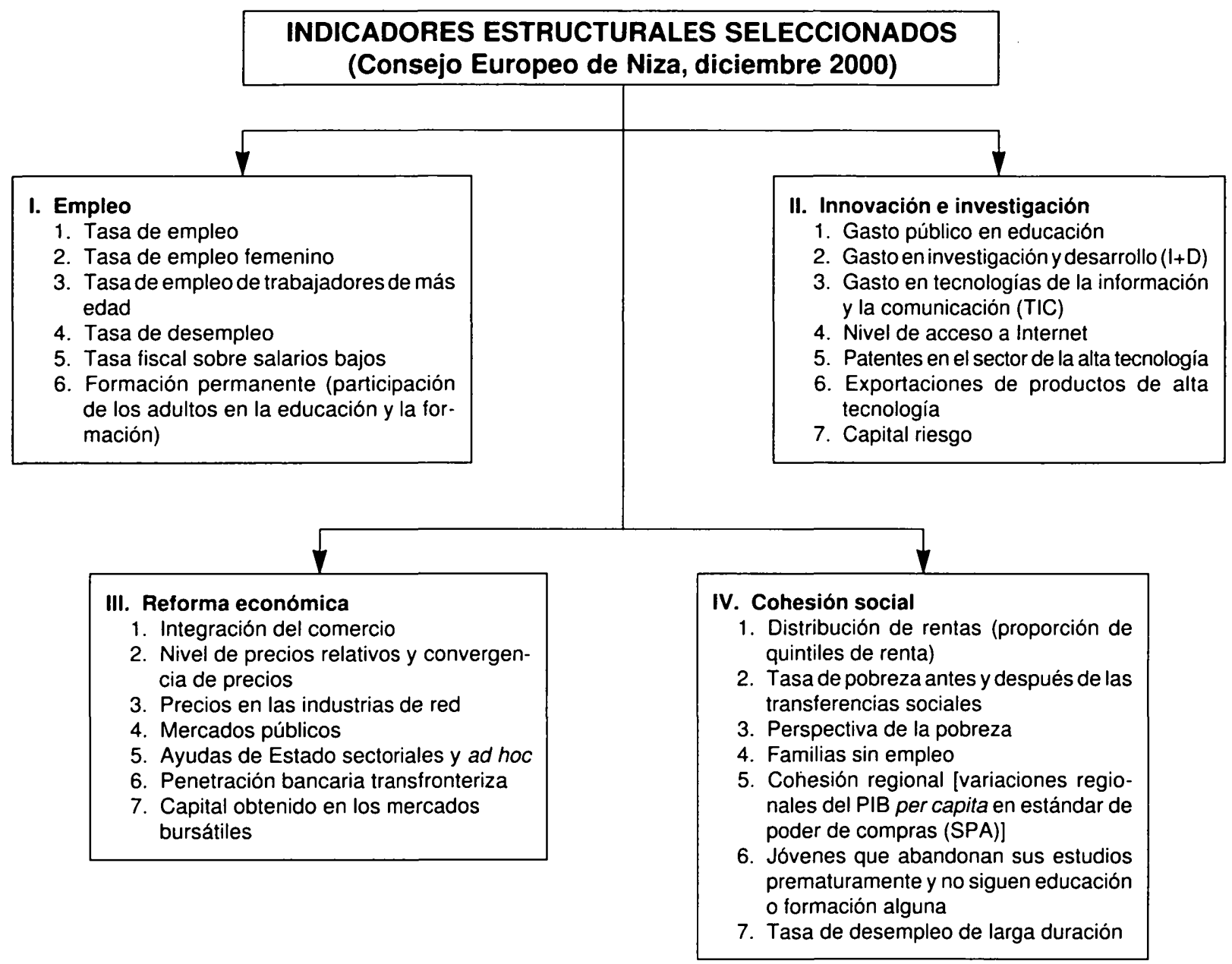

Fuente: Elaboración propia en base a Comunicación de la Comisión sobre Indicadores Estructurales, COM (2000) 594 final; Conclusiones Consejo Europeo de Niza (2000).

ha creado el Comité de Protección Social (refrendado por el Tratado de Niza, nuevo art. 144); se ha formulado el camino hacia una «estrategia concertada para modernizar la protección social» (Comisión, 1999), que se propone del mismo tenor que la Estrategia Europea de Empleo; se está aplicando el método abierto de coordinación a la lucha contra la pobreza y la exclusión social, con objetivos, planes nacionales, etc.; se está abordando la simplificación del Reglamento 1408/71, buque insignia de la coordinación de la seguridad social para hacer posible la libertad de circulación de los trabajadores europeos, y se está buscando el impulso político que permita la «modernización» de tan compleja arquitectura jurídica (Consejo Europeo de Estocolmo, 2001). En definitiva, se está avanzando, no posiblemente al ritmo que requiere una realidad cada vez más mundializada, pero la necesidad de la interacción entre el empleo y la protección social está llevando a esta última a ocupar el lugar que le corresponde en la Unión Europea, buscándose el equilibrio entre la subsidiariedad y la solidaridad.
Crear confianza en los ciudadanos europeos respecto a nuestros sistemas sociales es una tarea que tiene que ser abordada a nivel comunitario, ante los retos y las nuevas realidades sociales emergentes. Sería ingenuo, e incluso irresponsable, no inquietarse ante los desafíos de la evolución demográfica sobre el equilibrio de las finanzas públicas; pero, por el contrario, hay que dar respuesta definitiva a las preguntas que han estado presentes en la última década en la unificación europea: ¿introduce la construcción europea limitaciones para la reformulación de la política social?; ¿cómo se puede salvar la resistencia de algunos Estados miembros a avanzar más en el ámbito social, que no ha podido ser vencida, de momento, ni por el funcionamiento del mercado interior, ni por la acción comunitaria?; ¿tiene la diversidad de la política social de los países comunitarios una incidencia negativa en la consolidación del mercado único? Estas incertidumbres deben ser despejadas de un modo concluyente, por parte de las instituciones europeas. 
Finalmente, el objetivo estratégico surgido del Consejo Europeo de Lisboa de convertirnos en la economía basada en el conocimiento más competitiva y dinámica del mundo, para ganar credibilidad, requiere situar a los ciudadanos europeos como prioridad de dicha estrategia de la Unión. La calidad social, más y mejores empleos y con mayor cohesión social, puede ser una respuesta a estos retos, y constituirse en el futuro en un objetivo que confiera a la unificación europea, con los países candidatos a la adhesión, un alto valor y un sentido humano. La dimensión social de la construcción europea constituye la clave del éxito. No es posible asociar activamente a esta gran tarea a los ciudadanos europeos si su calidad de vida, de empleo y de protección social resultaran comprometidas. La Unión Europea del siglo XxI ha de ser el medio de preservar un modelo de sociedad europea abierta y generosa, con un nivel elevado de calidad social.

* Consejero de Trabajo y Asuntos Sociales. Representación Permanente de España ante la Unión Europea. Bruselas.

\section{Bibliografía}

Agence Nationale pour L'Ameloration des Condmons de Travall (2000), Le travail en mutation, 2000-2010, Spécial Colloque Européen, Changement, núm. 262

A $\llcorner B A, C$. (1995), «L'administration publique espagnole. Réforme ou modernisation?», Revue Française d'Administration Publique, núm. 75: 387-401.

Alonso Soto, F. (1998), Perspectiva del empleo en el siglo xxI (Europa y España), separata de la revista Documentación Social correspondiente al núm. 111.

ARGYRIS (1977), Organizational Learning and Management Information Sistems, Accounting, Organizations and Society.

Asociación Española para la Calidad (1999), Modelo EFQM de Excelencia, Madrid.

BABÉ Romero, Ignacio (1999), «El Modelo Europeo de Excelencia y los sistemas de Reconocimiento», Excelencia, núm. 23, abril: Club Gestión Calidad.

Beck, W.; Van der Maesen, L., y Walker, A. (eds.) (1997), «The Social Quality of Europe», obra colectiva Keuwer Law International, London, Boston: The Hague.

Bruto da Costa, A. (1997), «Social Policy and Competitiveness; The Social Quality of Europe», obra colectiva Keuwer Law International, London, Boston: The Hague.

Canales Aliende, J. M., «La producción de bienes y servicios y la concepción del administrado como cliente en el proceso de modernización administrativa», REGAB, núm. 5.

Cardell, S., y Johnson, M. (2000), «Planificar las Alianzas», Excelencia, núm. 26, Madrid: Club Gestión de Calidad.

Centro Europeo de Empresa y Confederación Europea de Sindicatos (2000), Proposition pour une Charte des Services d'intérêt général, Bruselas.

Comisión EUROPEA (1998), Gérer le changement; Rapport final du groupe d'experts de baut niveau sur les implications économiques et sociales des mutations indusrielles, Bruselas: DG Emploi \& Affaires Sociales.

- (1999), Cinco años de politica social, Forum especial.

- (1999), Estrategia concertada para modemizar la protección social, COM (1999) 437 final.
- (2000), La politica social y de empleo en Europa: una política para el ciudadano, DG Educación y Cultura.

- (2000), Agenda de Politica Social, COM (2000) 379 final.

- (2000), Objetivos estratégicos 2000-2005: Hacer la nueva Europa, COM (2000) 154 final.

- (2000), Tendencias sociales: perspectivas y retos, COM (2000) 82 final.

- (2000), Estrategias para el Empleo en la Sociedad de la Información, COM (2000) 48 final.

- (2000), Iniciativa y Leaming: pensar en la educación de mañana, Bruselas.

- (2000), Indicadores estructurales, COM (2000) 594 final.

- (2001), Europe 2002, COM (2000) 890 final.

- (2001), Aprovechar al máximo las capacidades de la Unión Europea: Consolidación y Ampliación de la Extrategia de Lisboa (Informe de sintesis para el Consejo Europeo de primavera, Estocolmo), COM (2001) 79 final.

- (2001), Cuadro de indicadores sobre la aplicación de la Agenda de Politica Social, $\operatorname{COM}(2001) 104$ final.

- (2001), Los servicios de interés general en Europa, DOCE (2001/C, 17/04).

- (2001), Corporate Social Responsibility; Draft discussion and issues paper on CSR

- (2001), European Conference, Social \& Labour MarketPolicies: Investing in Quality, Brussels.

- (2001), La contribución de las finanzas públicas al crecimiento y al empleo: mejorar la calidad y la sostenibilidad, DOC 6997/01.

- (2001), Rapport Européen sur l'Education et la Formation dans les Politiques de l'Emploi, DG Education et Culture.

- (2001), Comunicación de la Comisión «Políticas sociales y de empleo. Un marco para invertir en la calidad», 20-06-01; COM (2001) 313 final.

СомrтE Economico y Social (2000), La société civile organisée au niveau Européen, Actes de la première Convention, Bruxelles.

Comunidad Autónoma de Madrid (1998), Calidad en la Administración Pública, Madrid. 
Consejo Europeo de LuXEMBuRgo (1997), Conclusiones y anexos, SN 300/1/97, REV 1.

- CARDIFF (1998), Conclusiones $y$ anexos, SN 150/1/98, REV 1.

- Colonia (1999), Conclusiones y anexos, SN 150/99.

- Lisboa (2000), Conclusiones y anexos, SN 100/00.

- Ferra (2000), Conclusiones y anexos, SN 200/00.

- NizA (2000), Conclusiones y anexos, SN 400/00.

- Estocolmo (2001), Conclusiones y anexos, SN 100/01.

Colina, M.; Sala, F., y Ramirez, J. M. (1995), Derecho Social Comunitario, Valencia: Tirant lo Blanc.

Crosby (1987), La calidad no cuesta, Díaz de Santos.

Crozier (1970), La société bloquée, Senil.

Deming, M. E (1984), Calidad, Productividad y Competitividad, Madrid: Diaz de Santos.

DrUCKER, P. (1983), The concept of the Corporation, Nueva York.

European Foundation for Quautty MaNagement (1999), Modelo EFQM de Excelencia, Bruselas (http://www.efgm.org).

Feigenbaun, A. U. (1961), Total Quality Control, McGraw-Hill.

Fundación Europea para la Mejora de las Condiciones de Vida y de Trabajo (2001), Promouvoir la qualité de la vie au travail; services publics sociaux, Communiqué.

GALLEGo GIL, D., y ALONSO, C. (1995), «La organización que aprende: un enfoque proactivo para un contexto de calidad y competitividad, Capital Humano, núm. 84.

Garrat, B. (1990), Creating a Learning Organization. A guide to Leadship Leaming Development, Cambridge.

- (1992): «Creating a Learning Organization: Top management», EADA, núm. 33.

GARVIN, D. A. (1992), «Building a Learning Organization», Harvard Bussiness Review.

Gomis Diaz, P. L. (1999), La Politica Social y de Empleo en el Tratado de Ams. terdam, Madrid: Comité Económico y Social.

Heras Forcada, M. A. (1999), «Desarrollo e implantación de un Sistema de Indicadores asociado a la Calidad Total», Excelencia, núm. 24, Madrid: Club Gestión de Calidad.

Hurtado, R. (2001), «Normalización de los instrumentos financieros éticos», UNEM, núm. 148, Madrid: AENOR.

JeAntet, T. (2000), La economia social europea o la tentación de la democracia en todas las cosas, Valencia: Ministerio de Trabajo y Asuntos Sociales, CEPES y CIRIEC.

JimÉnez Latorre, F., y Romane Garcia, B. (2000), «Política de reforma estructural y el Proceso de Cardiff», Información Comercial Española, núm. 784, Madrid.

JuRAN, J. M. (1990), Juran y el liderazgo para la calidad, Diaz de Santos.

Marcos Hernández (2000), Modelo de Excelencia EFQM, Instituto de Estudios Superiores.

MiCKLETHWAT, J., y WOOLDRIDGE, A. (1998), La bora de los gurus, Madrid: Alianza Editorial.

Mirmi CluA, J. M. (1999), Calidad social y excelencia empresarial, X Congreso de Empresas de Calidad, Forum Qualitat, Barcelona.

Morales Garcia, Francisco (1999), «El Modelo EFQM como holograma: el criterio 9», Excelencia, núm. 24, julio, Madrid: Club Gestión de Calidad.
NaISBIT, J. (1998), Global Paradox, Jornadas profesionales de ESIC, Madrid.

NATONAL INSTTIUTE FOR WORKING LIFE (2001), «Work Life 2000. Quality in work; Diversity - respect and dignity; Prepare for a knowledge-based economy; Work organisation: development more than regulation», Newsletter, núm. 1 (http: lww.wwww.niwl.se/newsletter/01-1/diversity.asp).

OJEDA AVILEs, A. (1998), «La calidad social europea desde la perspectiva de los derechos fundamentales», Relaciones Laborales, núm. 1.

Osca Segovia, A. (2000), Calidad e Innovación en la Formación Continua, FORCEM.

Pérez Menayo, V. (1980), La protección del desempleo en España y en los paises de las CCEE, Madrid: IES.

- (1986), «La política de empleo en las Comunidades Europeas, evolución y tendencias actuales», Papeles de Economia Española, núm. 26, Madrid.

- (1987), Aspectos económico-financieros de la Seguridad Social. Estado actual del debate en la Comunidad Europea, Madrid: TGSS.

- (1987), La contribución de las iniciativas locales de creación de empleo en las CCEE, Madrid: Instituto de Estudios de Administración Local.

- (1988), «La financiación de la Seguridad Social en el contexto de la Comunidad Europea», Noticias CEE, núm. 42, Valencia.

- (1989 y 1990), Europa y el paro y Europa y la Seguridad Social, Madrid: Fundación Universidad Empresa.

- (1990), «La Cohesión Social en la Comunidad Europea», Revista de Estudios e Investigación de las Comunidades Europeas, Madrid.

- (1992), «¿Cohesión Social versus Cohesión Económica?», Aduanas, núm. 371 , junio.

- (1995), «El futuro de los sistemas de protección social», en la obra colectiva España en la Europa comunitaria: balance de diez años (editor Carlos MOLINA DEL Pozo), Madrid: F. Ramón Areces.

- (1996), «La gestión de calidad total y su aplicación a la Administración Públi. ca», obra colectiva Lecturas de Gerencia desde la Administración Financiera, Madrid: Instituto de Estudios Fiscales, Ministerio de Economia y Hacienda.

- (1998), «La calidad como yacimiento de la nueva gestión pública: la experiencia del Instituto Nacional de la Seguridad Social», Gestión y Análisis de Politicas Públicas, núm. 11-12, Madrid.

- (2000): «La modernización de la protección social en la Unión Europea ante los retos del siglo XXI», Información Comercial Española, núm. 784, Madrid.

- y Garde Roca (1996), «La Gerencia Pública como integración», obra colectiva Lecturas de Gerencia desde la Administración Financiera, Madrid: Instituto de Estudios Fiscales, Ministerio de Economia y Hacienda.

PIETERS, D. (1997), «Qualitative European Social Security Legislation», en la obra colectiva The Social Quality of Europe (editores BECK, MAESEN y WALKER), London, Boston: Keuwer Law International, The Hague.

Pollut, C. (1995), El gerencialismo y los Servicios Públicos, Madrid: Instituto de Estudios Fiscales.

ROURE, Juan (2000), «Valoración del criterio de Resultados de Clientes», Excelencia, núm. 28, Madrid: Club Gestión de Calidad.

SCHULTE, B. (1997), «Juridical Instruments of the European Union and the European communities», en la obra colectiva The Social Quality of Europe (editores BeCK, MaEsen y W WLKER), London, Boston: Keuwer Law International, The Hague.

Stein, G. (1999), El arte de gobernar seguin Peter Drucker, Barcelona: Gestión 2000.

Tejera Olvver, J. L. (2001), «Normalización en el campo de la ética», UNEM, núm. 148, Madrid: AENOR. 
ToLOSA, E. (2000), «Evaluación de las Alianzas externas según el Modelo EFQM de Excelencia en su versión de 1999», Excelencia, núm. 26, Madrid: Club Gestión de Calidad.

Tratados Consolddados de la Unión Europea y de la Comunidad Europea (1997), Bruselas.
UdAONDO DURÁs, M. (1999), «Cómo implantar en la empresa la Gestión del Conocimiento", Excelencia, núm. 22, Madrid: Club Gestión de Calidad.

UrTaGa, Alberto (2000), Nuevos caminos en el desempeño empresarial: la evaluación de le gestión ética, Forum Calidad 110/00. 
